\title{
Development of teacher guide for Grade 7 and 9 localized mathematics modules
}

Panopio, Jayverlie $\$

Alalum National High School, Philippines (jayverlie.mangubat@deped.gov.ph)

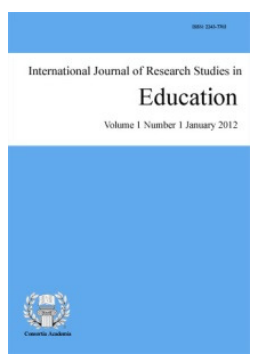

ISSN: $2243-7703$

Accepted: 25 October 2020

OPEN ACCESS

\section{Abstract}

A teacher guide provides specific guidelines on how to effectively use an instructional material to ensure that learners attain the expected content and performance standards. It offers the teachers with the necessary information on the various ways of presenting lessons in a more creative, engaging, interactive, and effective manner. It makes the delivery of instruction more convenient, and provides ease and flexibility for teachers to adopt different teaching styles, approaches and disciplines. Cognizant of the inherent value of a teacher guide for improved instruction, this study focused on the assessment of Grades 7 and 9 localized mathematics modules and the difficulties met by teachers in utilizing such modules, with an end view of developing a teacher guide to enhance the use of the localized modules. Specifically, this study identified the profile of the respondents in terms of gender, highest educational attainment, years of teaching of mathematics, and mathematics training/seminars attended as well as the teachers' assessment of the localized mathematics modules in achieving the learning competencies in Grades 7 and 9. In addition, significant differences in the assessment of the localized mathematics modules when grouped according to profile variables were subjected to hypothesis testing.

Keywords: localized modules; teacher guide; ANOVA; learning competencies; learning difficulties 


\section{Development of teacher guide for Grade 7 and 9 localized mathematics modules}

\section{Introduction}

Education has always played an active role in nation building, as it equips people with the necessary knowledge, and attitude for them to become a functional and productive member of the society. Education is also one of the strongest instruments for reducing poverty, by improving the economic and social well-being of people. However, to establish and maintain a high quality education system, strategic reform must be conceptualized, implemented and monitored for continuous quality improvement. The provision of quality education is the aim of the $\mathrm{K}$ to 12 curriculum. Enhancing the cycle of basic education by adding kindergarten and two years in high school ensures that graduates acquire the necessary skills and reach the employable age to qualify entrance into the world of work (Luistro, 2010). Its goal is to meet the demands of the world for globally competitive individuals and aims to provide Filipinos of better opportunities; the enhanced and decongested curriculum provides necessary concepts and life skills needed by Filipino learners as they proceed to the next stage of their life.

The spiral progression approach is used in the development of the curriculum, and is intended to be practiced in the classroom to help ensure that students achieve better mastery of concepts and skills. Under this approach, the complexity of the subject increases progressively. This shift is made more obvious in the secondary level where vertical articulation, or the seamless progression of competencies from the first grade of elementary to junior high school, is observed.

In the implementation of this relatively new curriculum, teachers are expected to find ways and opportunities that would allow them to explore ideas, acquire and synthesize new information, and frame and solve recurring problems. Indeed, the teachers play an important role to effectively implement quality instruction. Hence, the teachers' approach under the K to 12 curriculum should be learner-focused. They should really be the facilitators of learning, and therefore, they should refrain from dictation and commanding students to do activities without their presence. They should be able to engage the learners on how to be able to think, focus on higher order thinking skills, make decisions, and be able to apply concepts into real life situations. This is true in all subjects, especially those that have been perennially perceived as the most challenging for students, one of which is mathematics.

Promoting the efficiency and effectiveness among teachers is anchored on the need to improve mathematics instruction. Mathematics teachers need a broad horizon of knowledge on the characteristics of students, the theory of learning, the uses of media, and all aspect mathematical knowledge. Thus, teaching mathematics is really such a highly complex activity. Specifically, mathematics from K-10 is a skill based subject. By itself, it revolves on concepts such as quantities, shapes and figures, functions, logic and reasoning. Mathematics is also a tool of science and a language complete with its own notations, symbols and "grammar" rules, with which concepts and ideas are effectively expressed. However, the results of mathematics examinations have been a cause of concern for several years now.

The results of international and local tests and assessments reveal that schools nowadays are producing graduates with mediocre knowledge and skills in mathematics. Ocillos (2006) suggested that in order to improve the level of performance of students in mathematics, specifically in schools with low performance, school administrators should monitor classes, and increase support by providing text books and instructional materials.

Citizens of the modern world cannot afford to be ignorant in mathematics because the world is highly dependent on mathematical constructs. Hence, effective mathematical instruction has become an absolute necessity in all levels of education, particularly in the basic education level where mathematical foundation is laid and basic mathematical concepts are developed. For this, the $\mathrm{K}$ to 10 mathematics curriculum is expected to provide a solid foundation for mathematics is Grades 11 to 12 . Quality mathematics education in the higher level 
would only be possible if the mathematical foundation is solid and strong through the use of various strategies in mathematical instruction.

To teach students according to today's academic standards, teachers need to understand subject matter deeply and flexibly so they can help students create useful cognitive maps, relate one idea to another, and address misconceptions. Teachers need to see how the ideas connect across fields and to everybody's life. This kind of understanding provides a foundation for pedagogical content knowledge that enables teachers to make ideas accessible to others. As they strive to strengthen their teaching, quality teachers critically examine their practice, seek to expand repertoire, deepen their knowledge, sharpen their judgment, and adapt their teaching to new findings, ideas and theories.

Central to the present educational reforms is the curriculum/learning localization and contextualization, together with the harmonization of curriculum-related programs and projects. The former ensures that learning becomes culturally sensitive and relevant, while the latter answers the need to unify and strengthen curriculum support programs and learning opportunities for diverse learners. Both adhere in making the lesson flexible, fit, creative, relevant, meaningful, and adaptive to students' level of understanding and instructional needs.

The concept of localization, contextualization and harmonization falls on the idea that students learn best when experiences in the classroom have meanings and direct relevance in their lives. It helps teachers and students comprehend concepts by relating and presenting lessons in the context of the prevailing local environment, culture, and resources. Hence, lessons should become more real-life, customized, and appropriate.

In keeping up with the latest educational developments, mathematics modules were prepared in response to the goals set by the Department of Education to localize, indigenize and contextualize the instructional materials in mathematics. Localized mathematics modules for all levels were made by selected mathematics teachers. It took them almost a year in constructing the said materials. On May 16-20, 2016, mathematics teachers were gathered to validate the said module. There were errors found and these were readily corrected. The Department of Education (DepEd) mandated all teachers to utilize the said localized mathematics modules starting the school year 2016-2017.

The modules proved to be substantial, although some issues emerged during implementation and utilization. These issues were couples with the myriad of tasks that teachers are expected to do aside from other teaching related jobs. The time allotted for teacher's functions is sometimes not enough to cover all topics and another concern is the students' ability to catch up with the lesson. These cause difficulties among mathematics teachers in covering all the required competencies. Hence, teaching will be much easier with the help of a teacher guide.

A teacher guide provides guidelines on how to effectively use the instructional material to ensure that learners attain the expected content and performance standards. It offers the teachers with the necessary information to be able to teach the lessons in a more creative, engaging, interactive, and effective manner. It makes the delivery more convenient and provides ease and flexibility for teachers to adopt different teaching styles, approaches and disciplines. Currently, there is no available teacher guide for localized materials in mathematics. It is for this reason that the researcher, together with Ms. Cherie Belle C. Bautista, felt the need to develop a teacher guide for the localized mathematics modules of junior high school. This study had been a collaborative work of the two researchers. With this study focusing on the localized mathematics module for Grades 7 and 9, while Ms. Bautista concentrated on the localized mathematics modules for Grades 8 and 10.

\subsection{Statement of the problem}

This study assessed the localized mathematics modules in achieving the learning competencies in Grades 7 and 9 and the difficulties met by teachers in the utilization of the modules with the end view of developing a teacher guide to enhance mathematics teaching and learning. Specifically, the study will answer the following questions: 
$>\quad$ What are the demographic profile of Grades 7 and 9 teachers of mathematics in terms of: gender; highest educational attainment; years of teaching mathematics; and mathematics training/seminars attended?

$>$ How do the teachers assess the localized mathematics modules in achieving the learning competencies in Grade 7 and 9?

> Are there significant differences in the assessments on the localized mathematics modules when teachers are grouped according to profile variables?

$>$ What are the difficulties met in the utilization of the following localized learners' modules: Mathematics 7; and Mathematics 9?

$>\quad$ What teacher guide may be developed to enhance mathematics learning?

\subsection{Scope, delimitation and limitation of the study}

The study covered the assessment of the localized mathematics modules for Grades 7 and 9 with the purpose of developing a teacher guide to enhance instruction. It also determined the difficulties met by teachers in the utilization of the said modules. Relevant data were gathered and analyzed through the researcher-made questionnaire. The descriptive method of research was utilized in this study. Teachers who were handling other subjects and those teaching mathematics 8 and 10 are not included in the study. Mathematics teachers from private schools in the Division of Batangas, from any other level, are not also included. Other teachers from other divisions, public or private, from any other level are also excluded in this study. The study was limited to the response of 238 junior high school mathematics teachers in Grades 7 and 9 of Division of Batangas. The questionnaire was personally drafted by the researcher which focused on the assessment of the localized mathematics module in Grades 7 and 9 in achieving the learning competencies and the difficulties met in the utilization of the said modules.

\subsection{Significance of the study}

The study will be significant to the division office management, education program supervisor, curriculum implementers, school heads, mathematics teachers, other subject teachers, parents, students, present researcher, and the future researchers.

$\diamond \quad$ To the division office management and education program supervisor, this study will provide them with the needed teacher guide for the junior high school localized mathematics modules. It will lessen their work load in creating the said material. The output of this study may also be validated prior to its adoption in schools. This will also lead them to develop teacher guides for other year levels and for other subjects.

$\diamond \quad$ To the curriculum implementers, the result will be a basis to ensure the effectiveness, efficiency, sustainability, and impact of the implementation of the $\mathrm{K}$ to 12 basic education curriculum and the various curricular programs and projects, especially the use of localized materials.

$\diamond \quad$ To the school heads, it will help them in determining the difficulties met by mathematics teachers in using localized materials, which will prompt them to provide the necessary seminars and workshop. This will also encourage them to assess the learning materials used in other subjects.

$\diamond \quad$ To the mathematics teachers, this will provide them with a guide in using the localized mathematics modules more effectively. Moreover, it will challenge them to cover the expected learning competencies in each learning area and make them more flexible in the field of teaching.

$\diamond \quad$ To the other subject teachers, this study will inspire them to create ways to effectively materialize their 
localized and contextualized modules. This may lead to the development of their own teacher guide, and the creation of other materials that may help them in the field.

$\diamond \quad$ To the parents, the results of this research will motivate them in partnering with school in its aim to make learning fun and interesting. This will lead them to encourage their children to study the subject with enthusiasm and to use and see mathematics in their everyday living.

$\diamond \quad$ To the students, they will be more prepared to face the world of work because they will be equipped with the necessary skills expected for them to acquire under the K to 12 Basic Education Curriculum. Likewise, they will understand the lesson more as the flow of the teaching-learning process will have smoother and better transition.

$\diamond \quad$ To the present researchers, this study will allow them to learn and understand the need to localize and contextualize the teaching of mathematics. This will also make them realize the importance of having a teacher guide in the delivery of instruction.

$\diamond \quad$ To the future researchers, this will give relevant information as they pursue a study similar to this. This study will also serve as a baseline reference for future studies.

\section{Review of literature}

This part presents the review of conceptual and research literature used by the researcher to provide textual substance to the study. It also includes the theoretical and conceptual framework, the hypothesis and the definition of terms.

\section{Conceptual literature}

To enrich the study, the researcher reviewed the following literatures and analyzed them to have an in-depth presentation of concepts and pertinent information from several authorities. The discussion centers on the $\mathrm{K}$ to 12 Mathematics program, qualities of mathematics teachers, localized learner's modules, issues and challenges in $\mathrm{K}$ to 12 Math, and development of a teachers' guide.

\section{$2.1 \mathrm{~K}$ to 12 mathematics program}

Mathematics is one subject that pervades life at any age and in any circumstances. Thus, its value goes beyond the classroom and the school. Therefore, it must be learned comprehensively and with much depth. The framework is supported by the following underlying learning principles and theories: Experiential and Situated Learning, Reflective Learning, Constructivism, Cooperative Learning and Discovery and Inquiry-based Learning. The mathematics curriculum is grounded in these theories.

Mathematics at the secondary level returns to the linear sequential approach. As one of the indispensable learning areas in the restructured curriculum, it is considered a basic tool subject. In general, the time allotment in Mathematics has been increased, not necessarily to burden the learners with additional dispensable content, but to increase time for tasks and activities to help them gain mastery of basic competencies and reflect on contextualized content. As a tool subject, the lessons in Mathematics will be emphasized through innovative and interdisciplinary modes of instructional delivery. The Governance of Basic Education emissions a curriculum that shall promote the holistic growth of the Filipino learners and enable them to acquire the core competencies and develop the proper values. This curriculum shall be flexible to meet the learning needs of a diverse studentry as well as relevant to their immediate environment, social and cultural realities ( $\mathrm{K}$ to 12 Curriculum Guide).

The twin goals of mathematics in the basic education levels are critical thinking and problem solving the new mathematics curriculum ensures continuity of learning from kinder to Grade 10. Moreover, progression of topics at the secondary level is spiral, as opposed to the discipline-based mathematics in the old curriculum. The 
addition of grade 11 and 12 provides additional time for mastery of key mathematics concepts, plus an opportunity for students to choose advance mathematics as an elective (e. g. engineering and sciences, business and entrepreneurship, technical or applied mathematics). This curriculum follows the spiral approach wherein learning is a process of building upon previously learned knowledge. Through this, students are able to master the desired competencies by revisiting the subject several times and relating new knowledge or skills with the previous one. Moreover, students' progress on their learning as it entails going from simple to more complex knowledge or skills.

There are five content areas in the curriculum, as adopted from the framework: Numbers and Number Sense, Measurement, Geometry, Patterns and Algebra, and Probability and Statistics. The specific skills and processes to be developed are: knowing and understanding; estimating, computing and solving; visualizing and modelling; representing and communicating; conjecturing, reasoning, proving and decision-making; and applying and connecting. The following values and attitudes are to be honed as well: accuracy, creativity, objectivity, perseverance, and productivity. The use of appropriate tools is necessary in teaching mathematics. These include manipulative objects, measuring devices, calculators, computers, smart phones and tablet PCs, and the internet.

Numbers and Number Sense, as a strand include concepts of numbers, properties, operations, estimations, and their applications. Measurement as a strand includes the use of numbers and measures to describe, understand and compare mathematical and concrete objects. It focuses on attributes such as length, mass and weight, capacity, time, money and temperature, as well as applications involving perimeter, area, surface area, volume, and angle measure. Geometry as a strand includes properties of two - and three - dimensional figures and their relationships, spatial visualization, reasoning, and geometric modelling and proofs. Patterns and Algebra as a strand studies patterns, relationships, and changes among shapes and quantities. It includes the use of algebraic notations and symbols, equations, and most importantly, functions to represent and analyze relationships. Statistics and Probability as a strand is all about developing skills in collecting and organizing data using charts, tables, and graphs; understanding, analyzing and interpreting data; dealing with uncertainty; and making predictions about outcomes.

According to Prensky (2013), K to 12 studies focus on crucial areas of effective thinking that would include creative and critical thinking. The learning area standard of mathematics curriculum is for the learner to demonstrate understanding and appreciation of key concepts and principles of mathematics as applied - using appropriate technology - in problem solving, critical thinking, communicating, reasoning, making connections, representations, and decisions in real life.

The Grade 7 level standards is for the learner to demonstrate understanding of key concepts and principles of numbers and number sense (sets and real number system); measurement (conversion of units of measurement); patterns and algebra (algebraic expressions and properties of real numbers as applied in linear equations and inequalities in one variable); geometry (sides and angles of polygons); and statistics and probability (data collection and presentation, and measures of central tendency and variability) as applied - using appropriate technology - in critical thinking, problem solving, reasoning, communicating, making connections, representations, and decisions in real life. The first quarter of Grade 7 mathematics is about number and number sense. The content standard is for the learner to demonstrate understanding of key concepts of sets and the real number system while the performance standard is for the learner to be able to formulate challenging situations involving sets and real numbers and solve these in a variety of strategies.

The learning competencies include that the learner describes well-defined sets, subsets, universal sets, and the null set and cardinality of sets; illustrates the union and intersection of sets and the difference of two sets; uses Venn Diagrams to represent sets, subsets, and set operations; solves problems involving sets; represents the absolute value of a number on a number line as the distance of a number from 0 ; performs fundamental operations on integers; illustrates the different properties of operations on the set of integers; expresses rational numbers from fraction form to decimal form and vice versa; arranges rational numbers on a number line; 
performs operations on rational numbers; describes principal roots and tells whether they are rational or irrational; determines between what two integers the square root of a number is; estimates the square root of a whole number to the nearest hundredth; plots irrational numbers (up to square roots) on a number line; illustrates the different subsets of real numbers; arranges real numbers in increasing or decreasing order; writes numbers in scientific notation and vice versa; represents real-life situations which involve real numbers; solves problems involving real numbers.

The second quarter deals with measurement. The content standard is for the learner to demonstrate understanding of the key concepts of measurement and the performance standard is that the learner is able to formulate real-life problems involving measurements and solve these using a variety of strategies. At the end of the second quarter Grade 7 students must be able to illustrate what it means to measure; describe the development of measurement from the primitive to the present international system of units; approximate the measures of quantities particularly length, weight/mass, volume, time, angle and temperature and rate; convert measurements from one unit to another in both Metric and English systems; solve problems involving conversion of units of measurement.

Algebra starts in this quarter in which learners translate English phrases to mathematical phrases and vice versa; interpret the meaning of $\mathrm{n}$ where $\mathrm{n}$ is a positive integer; differentiate between constants and variables in a given algebraic expression; evaluate algebraic expressions for given values of the variables; classify algebraic expressions which are polynomials according to degree and number of terms; add and subtracts polynomials; and derive the laws of exponent. Students are also expected to multiply and divides polynomials; use models and algebraic methods to find the: product of two binomials, product of the sum and difference of two terms, square of a binomial, cube of a binomial, product of a binomial and a trinomial; solve problems involving algebraic expressions; differentiate between algebraic expressions and equations; differentiate between equations and inequalities; illustrate linear equation and inequality in one variable; find the solution of linear equation or inequality in one variable; solve linear equation or inequality in one variable involving absolute value by: graphing and algebraic methods; solve problems involving equations and inequalities in one variable.

The third quarter of grade 7 mathematics is about geometry. The learner demonstrates understanding of key concepts of geometry of shapes and sizes, and geometric relationships and is able to create models of plane figures and formulate and solve accurately authentic problems involving sides and angles of a polygon. Specifically, the learners must be able to represent point, line and plane using concrete and pictorial models; illustrate subsets of a line; classify the different kinds of angles; derive relationships of geometric figures using measurements and by inductive reasoning; supplementary angles, complementary angles, congruent angles, vertical angles, adjacent angles, linear pairs, perpendicular lines, and parallel lines; and derive relationships among angles formed by parallel lines cut by a transversal using measurement and by inductive reasoning. In addition, students must use a compass and straightedge to bisect line segments and angles and construct perpendiculars and parallels; illustrate polygons: convexity, angles and sides; derive inductively the relationship of exterior and interior angles of a convex polygon; illustrate a circle and the terms related to it: radius, diameter chord, center, arc, chord, central angle, and inscribed angle; construct triangles, squares, rectangles, regular pentagons, and regular hexagons; solve problems involving sides and angles of a polygon.

The fourth quarter deals with statistics and probability, which enable the learners to demonstrate understanding of key concepts, uses and importance of statistics, data collection/gathering and the different forms of data representation, measures of central tendency, measures of variability, and probability, collect and organize data systematically, compute accurately measures of central tendency and variability, and apply these appropriately in data analysis and interpretation in different fields. The learning competencies include explaining the importance of Statistics; posing problems that can be solved using Statistics; formulating simple statistical instruments; gathering statistical data; organizing data in a frequency distribution table; using appropriate graphs to represent organized data: pie chart, bar graph, line graph, histogram, and ogive; illustrating the measures of central tendency (mean, median, and mode) of a statistical data; calculating the measures of central tendency of 
ungrouped and grouped data; illustrating the measures of variability (range, average deviation, variance, standard deviation) of a statistical data; calculating the measures of variability of grouped and ungrouped data; using appropriate statistical measures in analyzing and interpreting statistical data; drawing conclusions from graphic and tabular data and measures of central tendency and variability (Mathematics Curriculum Guide).

Grade 9 mathematics is focused on patterns and algebra, as well as geometry. After the first grading period, the learners must be able to demonstrate understanding of key concepts of quadratic equations, inequalities and functions, and rational algebraic equations and be able to investigate thoroughly mathematical relationships in various situations, formulate real-life problems involving quadratic equations, inequalities and functions, and rational algebraic equations and solve them using a variety of strategies. On the second period, the learners demonstrate understanding of key concepts of variation and radicals and are able to formulate and solve accurately problems involving radicals. On the third period, Grade 9 students must demonstrate understanding of key concepts of parallelograms and triangle similarity and are able to investigate, analyze, and solve problems involving parallelograms and triangle similarity through appropriate and accurate representation. Lastly, on the fourth grading period, they must demonstrate an understanding of the basic concepts of trigonometry and are able to apply the concepts of trigonometric ratios to formulate and solve real-life problems with precision and accuracy.

The learning competencies of grade 9 mathematics on the first quarter include illustrating quadratic equations; solving quadratic equations by extracting square roots, factoring, completing the square, and using the quadratic formula; characterizing the roots of a quadratic equation using the discriminant; describing the relationship between the coefficients and the roots of a quadratic equation; solving equations transformable to quadratic equations (including rational algebraic equations); solving problems involving quadratic equations and rational algebraic equations; illustrating quadratic inequalities; solving quadratic inequalities; and solving problems involving quadratic inequalities. Further, they should be competent at modeling real-life situations using quadratic functions; representing a quadratic function using table of values, graph, and equation; transforming the quadratic function defined by $y=a x^{2}+b x+c$ into the form $y=a(x-h)^{2}+k$; graphing a quadratic function: domain, range, intercepts, axis of symmetry, vertex, direction of the opening of the parabola; analyzing the effects of changing the values of $\mathrm{a}, \mathrm{h}$ and $\mathrm{k}$ in the equation $y=a(x-h)^{2}+k$ of a quadratic function on its graph; determining the equation of a quadratic function given a table of values, graph, and zeros; and solving problems involving quadratic functions.

On the second quarter, the learners are expected to illustrate situations that involve the following variations: direct; inverse, joint, and combined; translate into variation statement a relationship between two quantities given by: a table of values, (a mathematical equation, a graph, and vice versa; solve problems involving variation; apply the laws involving positive integral exponents to zero and negative integral exponents; illustrate expressions with rational exponents; simplify expressions with rational exponents; write expressions with rational exponents as radicals and vice versa; derive the laws of radicals; simplify radical expressions using the laws of radicals; perform operations on radical expression; solve equations involving radical expressions; and solve problems involving radicals.

The learning competencies that should be achieved on the third quarter comprise identifying quadrilaterals that are parallelograms; determining the conditions that make a quadrilateral a parallelogram; using properties to find measures of angles, sides and other quantities involving parallelograms; proving theorems on the different kinds of parallelogram (rectangle, rhombus, square); proving theorems on trapezoids and kites; describing a proportion; applying the fundamental theorems of proportionality to solve problems involving proportions; illustrating similarity of figures; proving the conditions for similarity of triangles: SAS similarity theorem, SSS similarity theorem, AA similarity theorem, right triangle similarity theorem, special right triangle theorems; applies the theorems to show that given triangles are similar; proves the Pythagorean Theorem and solves problems that involve triangle similarity and right triangles. 
Grade 9 students are also expected to illustrate the six trigonometric ratios: sine, cosine, tangent, secant, cosecant, and cotangent; find the trigonometric ratios of special angles; illustrate angles of elevation and angles of depression; use trigonometric ratios to solve real-life problems involving right triangles; illustrate laws of sines and cosines; and solve problems involving oblique triangles.

\subsection{Qualities of mathematics teachers}

According to Cochran-Smith (2004), teacher quality is one of the most, if not the most, significant factor in students' achievement and educational improvement. Teachers have a lot of roles in the learning activity around the classroom. As a manager of the classroom situation, the teacher is also responsible for setting up the physical environment most conducive to learning. Such conditions are lighting, ventilation and room appearance. In addition to this, the teacher must be aware of the safety environment where the students are moving. It is generally recognized that the teachers play a key role in bringing about educational reform, and that the teachers' professional development is crucial for the desired change to take place. Educational reform efforts are doomed to fail if emphasis is on developing specific teaching skills, unless the teaching cognitions including their belief, intentions and attitudes are taken into consideration.

Zuleta (2008) explains that there are various investigations and researches to define and establish scientifically about the characteristics of an effective teacher. The result of the studies generally attributes to two major categories in which the distinguishing characteristics of an effective teacher may be group into personal qualities and professional qualities. Personal qualities refer to teachers' personality such as his philosophy, interest, attitudes, beliefs, emotional maturity, and his interrelation with students, co-teachers, administrators, non-teaching personnel, in the manner he respond to various situations and how these people respond to his behaviors.

On the other hand, professional qualities refer to teacher's knowledge of the subject matter to be taught, his understanding of psychological and educational principles, theories, and concepts, the pedagogical methods and strategies as well as high regard and appreciation to the teaching profession. Effective teachers must have the mastery of the subject matter. Mastery of the subject calls the teacher expertise in their own field. The teacher must be able to present the lesson logically, systematically, and analytically. They are able to use strategies which they feel are effective on the type of pupil/students they have. The teachers should encourage the pupils/students to ask questions to give their view, reactions and comments.

Canonizado (2009) said that the teacher is responsible for creating an intellectual environment in the classroom where serious engagement in mathematical thinking is the norm. Effective teaching requires deciding what aspects of a task to highlight, how to organize and concentrate the worth of students, what questions to ask the pupils having varied levels of expertise, and how to support pupils without taking over the process of thinking for them. Selecting and using suitable curricular materials using appropriate instructional tools and technique to support learning, and pursuing continuous self-improvement are actions that good teacher take every day. In addition, a teacher should present the subject matter skillfully making interaction with the students, introducing the methods and applying various aids. Every problem should be introduced to the students logically and systematically. He should first judge the value of the students then he should apply different methods to make his teaching more effective and comprehensive.

According to Tulio (2008), the teacher is involved with the establishment of effective procedures so that class activities proceed with efficiency and with the least expenditure of time and energy on the part of both teachers and students. Moreover, as a facilitator, the teacher must be knowledgeable of alternative approaches to teaching. The teacher has to bear in mind that there is no single perfect approach to teaching which will help every student learn everything in every way. Furthermore, as evaluator, the teacher is expected to understand the most effective use of reliable and valid instruments of evaluating the outcome of learning and diagnosing learning difficulties of the students. Teachers must understand the various theories of measurement and 
evaluation of student's performance.

It is said that education today requires teachers who can assume the responsibility of a generation who can think and act with the meaning of functional democracy of technological advances and psychological aspects of individuals and groups. In brief, they must be imbued with wholesome personality and trained well in reliable institutions. It is an accepted fact that there are many teachers who cannot mold the youth because they themselves need to be given intensive training in the profession to develop positive attitudes and values towards the chosen field of work.

In relation to this, DepEd Order No. 7, s. 2015 entitled "Hiring Guidelines For Teacher I Positions Effective School Year (SY) 2015-2016)" aims to integrate and further institutionalize the primary objective of the K to 12 Basic Education Program, which is to enhance the overall quality of basic education in the country by hiring highly-competent teachers, and to uphold the Department's mandate under the Magna Carta for Public School Teachers (Republic Act 4670) to promote and improve public school teachers' employment and career opportunities as well as to attract more people with proper qualifications to the teaching profession. Based on the guidelines, the Department of Education (DepEd) recognizes that the success of any education system greatly relies on the competence of its teachers. Hence, one of the primary issues the Department aims to address through its comprehensive implementation of the $\mathrm{K}$ to 12 Basic Education Program is the need for highly competent teachers in public elementary and secondary schools. The program plans to achieve this objective through significantly improving professional standards that will better ensure that the teachers hired are able to substantially contribute to the development of lifelong learners. Furthermore, the hiring system is also set to provide opportunities for the absorption of all qualified kindergarten volunteers and LGU-hired teachers into the national plantilla.

Faithful to the merit and fitness principle of the Civil Service Doctrine of the Constitution and DepEd's continuing thrust to enhance the quality of basic education, these hiring guidelines are hereby promulgated for Teacher I positions consistent with the pertinent provisions of existing laws, rules and regulations effective School Year 2015-2016. An applicant to Teacher 1 refers to a person who holds a valid certificate of registration/professional license as a teacher from the Professional Regulation Commission (PRC) seeking to be appointed to a Teacher I Position. Qualified applicant refers to an applicant who has been screened and who, therefore, meets the evaluation and selection criteria used by the Schools Division as provided for in the enclosed guidelines. Applicants shall be evaluated using the following criteria: education (20 points), teaching experience (15 points), LET/PBET rating (15 points), specialized training and skills (10 points), interview (10 points), demonstration teaching (15 points) and communication skills (15 points).

Education shall be rated in terms of the applicant's academic achievement. Thus, all subjects with corresponding units must be included in the computation. Applicants with non-education degrees shall be rated using their GWAs in their baccalaureate degrees and the eighteen (18) professional units in education. If the school issues a certification of GWA with a corresponding percentage rating that does not conform to the above table, the committee shall refer to the GWA grading system of the school. For schools with unique grading systems, a corresponding transmutation table shall be constructed. Applicants with a Master's Degree (MA or MS) shall be given +1 point, while applicants with a Master's Degree and with a Doctorate (PhD) shall be given +2 points. Teaching experience in Early Childhood (EC) kindergarten/preschool, elementary, secondary, tertiary, higher education, Special Education (SPED), Alternative Learning System (ALS), Technical-Vocational Education and Training (TVET), learning institutions offering culture-based education programs for indigenous peoples (IP) - even prior to passing the LET - shall be given 1.50 points for every school year but shall not exceed twelve (12) points. For every month of service, 0.15 point shall be given.

Generally teachers must convey ideas and information clearly; provide reasonable examples of effective lesson-planning, instructional strategies, and/or student assessment; make content meaningful to students in the district; set concrete, ambitious goals for student achievement; address the multiple and varied needs of students; 
focus on achieving results with students; indicate confidence that all students should be held to high standards; maintain high expectations for students when confronted with setbacks; continue to focus on the students' academic success and reflect on successes and failures. Their teaching ability demonstrates an appropriate knowledge of content and pedagogy. The teachers' knowledge of content and pedagogy must be extensive, showing evidence of a continuing search for improved practice. Teachers must actively build on knowledge of prerequisites and misconceptions when describing instruction or seeking causes for student misunderstanding. The teachers' spoken and written language is correct and expressive, with well-chosen vocabulary that enriches the lesson.

Qualified applicants must assume accountability for classroom environment and cultures; convey reasonable understanding of potential challenges involved in teaching in a high-need school; demonstrate ability to deal effectively with negative student behavior; persist in offering viable or realistic strategies to deal with classroom management challenges; remain productive and focused when faced with challenges; convey willingness to try multiple strategies or something new when things change or when confronted with challenges and display willingness to adapt classroom management style to meet the particular needs or culture of a school. They demonstrate ability to deal effectively with negative student behavior. Qualified teachers also respect the opinions of others and recognize the impact of families to student's performance. Their strategies create positive relationships with administrators, faculty, and students. They express personal and professional expectations and/or preferences that are in line with the school culture; demonstrate interests and skills that match the school's culture and needs; and interact appropriately with supervisors, colleagues, parents and students. They demonstrate skills and needs for development that can be a good fit with the school.

\subsection{Localized mathematics learner's module}

Localization is the process of adapting and relating the content of the curriculum and the process of teaching and learning to local conditions, environments, and resources. Meanwhile, contextualization is the process of presenting lesson in meaningful and relevant context based on previous experiences and real-life situations. The concept of localization and contextualization falls on the idea that students learned best when experiences in the classroom have meanings and relevance in their lives. Things students do and associated with them are the learning that last forever. Applying the rule for learning by doing, applied learning, and manipulative learning is also a must in executing localization and contextualization in teaching. If students were put in an actual learning environment letting them to manipulate, relate, and adapt to various learning opportunities and resources available within the locality or community, profound learning will be assured and realized. It helps teachers and students comprehend concepts by relating and presenting lessons on the context of the prevailing local environment, culture, and resources. Hence, lessons become more real-life, customized, and appropriate.

Nonetheless, teachers should be adaptive and creative in using localization and contextualization in teaching. Such principles were made and adapted in the academe to make the curriculum respond, conform, reflect, and be flexible to the needs of the learners, especially the $21^{\text {st }}$ century learners who need to be holistically and skillfully developed. It is true that sometimes people understand more the concepts by relating them to ideas that they can easily comprehend, appreciate, and relate in their lives, but the standards of quality and relevant education should always be considered all the times and should not be compromised just for the sake of localized and contextualized lesson (Chapin, 2000).

If students clearly see how coursework connects to their goals, interests, and concerns, they will be more likely to value it, and thus more motivated to invest time and effort. Students will be more motivated to work if they know what goals they are working towards. Thus, it is a good idea not only to articulate goals for the course, but also for specific lectures, discussions, and assignments (Roblyer, 2000). Thus, pursuant to Republic Act 10533, or An Act Enhancing the Basic Education System by Strengthening Its Curriculum, particularly section 5 of paragraph 4 , the curriculum shall be contextualized and global; and paragraph 8 , the curriculum shall be flexible enough to enable and allow schools to localize, indigenize, and enhance the same based on their 
respective educational and social context, this office reiterates the use of Curriculum and Learning Management Division (CLMD) framework guide and tools in localizing/ indigenizing and contextualizing materials as reference.

In connection with this, the Curriculum and Learning Management Division (CLMD), together with Mathematics Instructional Leaders (SDOs) shall start to localize, indigenize, and contextualize learning materials in grades 1 to 4 and grades 7 to 10 effectively July 2015 to February 2016 (Regional Memorandum 6795, July 16, 2015). The implementation of the basic education curriculum which is strengthened by localization and systematized management of curriculum programs and projects, needs a paradigm shift in the way RO and DO education program supervisors ' are performing their functions. Certainly, there is a need to rebuild capabilities and work orientations to ensure effectiveness and efficiency in the performance of the new functions. The challenges brought about by the present national reforms alongside the $\mathrm{K}$ to 12 basic education curriculum can certainly require well-trained and well-capacitated curriculum specialists to best implement the new system.

The goal of the Curriculum and Learning Management (CLM) System is to support the curriculum managers and implementers in ensuring the effectiveness, efficiency, sustainability, and impact of the implementation of the $\mathrm{K}$ to 12 basic education curriculum and the various curricular programs and projects. To achieve this goals the division has the function and that is to ensure full implementation of the articulated basic education curriculum through localization/indigenization and innovations in teaching the various subject-areas towards improvement in the quality of learning outcomes and to improve provision and availability of quality learning and teaching resource materials for students and instructional support materials for teachers in the division.

The school heads and teachers also have roles and responsibilities which include the conduct of school orientation/advocacy on the region-wide implementation of the Regional Program Framework, Standards and Implementation Plan and Division Implementation Plan of the National K to 12 BEC Localized Curriculum; implement continuing school-based T\&D Programs for teachers on the implementation of the national and localized curriculum; enrich the Division Curriculum Localization Matrix (DCLM) and develop a School Curriculum Localization Matrix (SCLM) as integrated into the national curriculum; implement the development, production, and the utilization and access to quality localized/ indigenized learning resources through the LRMD System. Moreover, the school heads and teachers are responsible to undertake school action research with focus on the effectiveness/ impact of the $\mathrm{K}$ to 12 curriculum including its localization and utilization of results/findings for decision-making and improvement of teaching-learning process and the conduct of advocacy and mobilization of support from external stakeholders, media, GOs, NGOs.

They must also to integrate the use of local content and learning process as feature in classroom instruction/observation; use learning strategies such as interschool visitation and sharing of best practices; identify the school's development needs on the curriculum and instruction, the localization of the curriculum and integrate these into the School Implementation Plan (SIP); prepare report of documented activities related to the implementation of the localized curriculum that should be submitted to the division and communicated to all concerned.

Program implementation of the $\mathrm{K}$ to 12 Basic Education Curriculum and the special programs and projects need to be supported by region-wide efforts in curriculum localization. Curriculum localization takes a center stage in making education more relevant and culturally responsive catering to the needs of the target clientele. Primarily, local content, local language, local learning process and local resources must be taken into consideration for the localization of the curriculum. Relevance of the curriculum is also assured by the localization of the learning resources. The LRMDS has been installed to support the development of new materials and aligning existing ones to the demands of the $\mathrm{K}$ to 12 Curriculum. Moreover, it is important that efforts in this area must follow the procedures and standards set by the LRMDS (Regional Memorandum No. $8 \mathrm{~s}$. 2015). 
In keeping up with the latest developments in the $\mathrm{K}$ to 12 curriculum, modules were prepared in response to the goals set by the Department of Education to localize, indigenize and contextualize the instructional materials in Mathematics. These modules utilize the latest concepts and techniques in the teaching and learning mathematics processes. The strategies are promoted through introducing specific objectives and mathematical concepts and carefully presenting and explaining illustrative examples and problems. The authors hope that this module will succeed in improving the students, teachers and the readers in general, understand concepts of junior high school mathematics (Localized Mathematics Module 7, 2016).

Ala eh Grade $7 \mathrm{~K}$ to 12 Mathematics is primarily designed to provide students with localized, indigenized and contextualized material in Mathematics pursuant to Republic Act 10533 as prescribed in the $\mathrm{K}$ to 12 Curriculum. The special feature in this module is the presentation and the inclusion of topics relative to local life situations and problems which are commonly encountered within the community. In this way, the learner will better understand and appreciate the concepts because of its realistic and concrete application involving the five strands of Mathematics in K to 12 Curriculum namely, Numbers and Number Sense, Measurement, Algebra, Geometry and Statistics. Ala eh Grade $7 \mathrm{~K}$ to 12 Mathematics begins each chapter with a unit picture depicting the context. It includes a brief introduction discussing the significance of the topics and its essence in dealing with real-life situations. The book observes the 4A's format which stands for Activity, Analysis, Abstraction, Application and Closure. However, to avoid redundancy, the authors opted to use phrases or sentences to stand for each.

Each lesson begins with an activity to stimulate the engagement and enthusiasm of the learners. It is followed by Analysis labeled Let's Talk About It, which consists of a series of questions that elicit ideas geared towards the learning of the concept. These questions can be used by the teacher to guide the learners towards the formulation of the generalization or crystallization of their understanding. Let's Wrap it Up is the Abstraction phrase which presents and formalizes the content of the lesson. This includes terms to remember, formulas and examples with complete solutions which direct the learner to the application phrase labeled as Let's Try It. It consists of exercises to be answered by either analysis or computation. The Closure is the parting statement or task that will help develop retention of the concepts learned. It is optionally titled in this book as Let's Practice that enwraps the learner to appertain the skills acquired in the lesson. The special feature of the localized modules are expected to inspire and spur the learners to achieve better mathematical competency and better equipped in life. It is further hoped that it will be instrumental in developing greater interest among students to engage in and do mathematics (Localized Mathematics Module 7, 2016).

\subsection{Issues and challenges in $K$ to 12 mathematics}

Roblyer (2000) emphasized that the students must appreciate and understand the value of mathematics in society. One of mathematics teacher's great challenges is to connect mathematics to the real world in ways that the students understand and appreciate. To be well-informed as adults and to have access to desirable jobs, students today require an education in mathematics that goes far beyond what was needed by the students in the past. All students must develop and sharpen their skills, deepen their understanding of mathematical concepts and processes and have their problem-solving, reasoning and communication activities while using mathematics to make sense of, and to solve compelling problems. All students need a deep understanding of mathematics, for this occur vigorous mathematical context must be organized, taught and assessed in a problem-solving environment. For students to develop this deeper level of understanding, their knowledge must be connected to a variety of ideas and skills across topic areas and grade level in mathematics, to other subjects taught in school, as well as to situation outside the classroom.

According to Medoff (2013), one way of teaching mathematics is to provide a variety of activities and supports. Tasks deliberately selected, and problems that relate to the students current lives. It is important, especially in middle school, to make tasks concrete and related to the present, rather than to a possible future. Kids are given time and space to be as physically active as possible. Students must be actively engaged in doing 
mathematics. They should not be sitting back watching other students solve problems. Mathematics is a stimulating and interesting field generating new knowledge every day, and students should be exposed to this excitement and challenge, using real world example if possible. Tujan (2004) stated that people perform best in the school of experience. When students see that learning has a purpose, they are more likely to stay engaged.

One effective way to harness student motivation is to have students apply what they are learning to real-world contexts. Also, motivation is often enhanced when instructors connect course material to students' personal interests. One possible way to enhance student motivation is to allow students to choose topics for papers and projects that connect the course content to their outside interests and passions. This can lead them to engage more deeply than they had initially planned and to discover value they had overlooked (Anderson, 2003). Meanwhile, Dossey et al. (2002) gave emphasis to the fact that the traditional factor must not be totally put to waste because even the most traditional books can be of good use. The teacher spends most of his time in class in analyzing the textbook. The approach of the teacher in teaching a course is the basis, whether a class is discovering oriented or not. The teacher may not have the misconceptions that they are slaves of textbooks.

The improvement of the education, which anchored primarily on building more school, hiring and training more teachers and producing more books. According to him, what is really needed to be done, is to understand the nature of the learners and to adapt around that understanding in the goals, tools and methods of education. The learner should first acquire the essential encoding and decoding skills before exposing them to books. It is also necessary to develop a more sensitive and meaningful assessment and grading system excluding transmutation, recitations, homework and projects. The learner should be graded solely based on their encoding and decoding skills. In addition, teachers must be relieved from preparing the daily lesson plans, instead, they are provided by prepared and flexible lesson plans complete with developmental goals, dynamic strategies and activities, sensitive assessments with learning tools so they can concentrate in teaching and monitor the improvement of their learners. Lastly, it is essential that the students be equipped with the appropriate technology in sufficient quantities enabling them to improve their low-achieving students.

Schools across the country are adopting new approaches to teaching and learning in order to prepare students for life in a technology-rich world. Yet as schools break away from traditional models of education, new challenges emerge. The top four challenges are creating opportunities for authentic learning; supporting students' non-cognitive and social-emotional skill development; fostering deeper learning; and supporting students' ability to solve real world math problems. Authentic learning pertains to approaches that encourage students to learn through hands-on, collaborative projects that address real problems relevant to their lives. Challenge-based, problem-based, project-based, and civic learning through community engagement are approaches that share a common interest in authentic learning. Students who participate in guided collaborative projects improve critical thinking and social skills needed for college and careers. Further, authentic learning has the potential to make students more engaged. This is important, as students who are not engaged in learning are more likely to drop out of school.

The most challenging thing about implementing challenge-based learning in schools is changing the mindset of students and teachers. Students must learn the process for problem solving, which requires more time asking questions before jumping to solutions. On the other hand, teachers must empower students to be completely in charge of how they learn the standards. Non-cognitive skills are the behaviors, qualities, and skills that help students to be successful in school and life - and these are not connected directly to a subject or content area. The non-cognitive skills include academic behaviors, academic perseverance, academic mindsets, learning strategies, and social skills. Mainstream media often describe specific student qualities or behaviors, such as persistence, self-discipline, focus, confidence, teamwork, organization, seeking help, and staying on task.

Social-emotional learning is a child's ability to experience, manage, and express emotions; develop close relationships with others; and actively explore his or her environment and learn. Supporting students' non-cognitive development is challenging because it requires teachers to adopt a new mindset, different from the 
traditional view of teachers as content experts. To best support students' non-cognitive skills, she says teachers must begin to see students as teachers, and provide student-driven lessons that enable students to take the lead role in learning. Diverse group of learners allow everyone on the team to collaborate and learn from one another.

Deeper learning encompasses the skills, understandings, and mindsets students need to succeed in college and career. This includes non-cognitive skills such as self-discipline and collaboration, as well as academic knowledge and critical thinking. Further, deeper learning develops students' creativity and innovation, and information and technology literacy necessary to thrive in a digital world. Students enrolled in deeper learning programs improve their problem-solving skills and are more likely to graduate on time, they advance more quickly in interpersonal and intrapersonal skills than students in other programs. Deeper learning is also crucial for the health of the society and economy. Employers want employees who are able to communicate effectively and work in teams. Even more important: students will face extremely complex problems as they enter the workforce, such as rapid climate change and poverty. They will need to work collaboratively and apply knowledge in new ways to develop innovative solutions.

Technology develops deeper learning skills such as collaboration and communication as they connect with people across the globe. The most difficult part of implementing deeper learning is moving teachers from the traditional setting to expanding their classrooms beyond what they are comfortable with. It takes time, strategy, and rethinking professional development. For some teachers, the strategies may be a very new way of thinking about learners and the classroom environment, which requires them to take risks in their teaching.

Mathematical concepts and problem solving skills are essential for success in everyday life, including for understanding finances, politics, social relationships, and the arts. In order to successfully solve real-world math problems, students need to apply basic math concepts to new challenges. The new Common Core standards for math, as well as other college and career-ready standards, require students to develop real-world math skills. Specifically, students develop conceptual understanding, or a deep understanding of how math works, and then learn to apply concepts when faced with new or different problems. Simply memorizing math equations and solutions is no longer sufficient. The ability to apply math concepts to real-world situations is also essential for success in STEM (Science, Technology, Engineering and Math) careers.

It is difficult to fully adopt real-world math because it requires a complete redesign of what learning looks like. Teachers, schools and districts must take a huge risk to move outside the current structure based on set math textbooks and standardized tests. Further, it is time-consuming to recruit community partners for real-world projects. Despite these challenges, teachers shall regularly assign students real-world math projects such as researching college fees and tuition costs in order to learn about exponential growth.

\subsection{Development of teacher's guide}

Salazar (2001) concluded in her article that effective teaching and learning in mathematics do not happen incidentally. Everything must be organized, planned and created. Granted that some of the best learning could be informal, spontaneous and incidental, for long term sequential learning to occur inside the classroom, the teacher must be knowledgeable of the best condition for teaching and learning. Such condition must be supported with the necessary and appropriate instructional materials to support teacher in carrying all the activities in the classroom. Wesley and Wronski (2003) asserted that instructional materials have long been part of the educational system. According to them, textual source has made significant contribution to man's knowledge yesterday and today, and that it can perform vital service tomorrow. This is the reason why subject matter specialists always emphasized the use of textbook and other supplementary materials in teaching.

The profession of teaching is varied, the job of an elementary school teacher is very different from the job of a college professor - different material is taught, and different methods are used. But certain aspects of teaching are the same at all levels. Teachers must plan their lessons and present them in a way that interests students and helps them understand what is being taught. They must measure and evaluate their students' progress. The 
teacher is the key to passing on to the next generation the best that people have thought and done (The New Book of Knowledge, 2003).

According to Glisan and Shrum (2005), teachers are active decision makers who use opportunities to apply theory by observing classroom interaction, designing and teaching their own lessons and making appropriate decisions in a wide variety of situations. A Teacher's Handbook assists teachers as they begin their journey toward accomplished teaching by basing their learning, teaching, and reflecting on the five propositions established by the National Board for Professional Teaching Standards: teachers are committed to students and their learning; teachers know the subjects they teach and how to teach those subjects to students; teachers are responsible for managing and monitoring student learning; teachers think systematically about their practice and learn from experience; and teachers are members of learning communities.

Teachers learn to interpret their worlds (e. g., their subject matter, their classroom context, and the people in it) and to use these interpretations to act and react appropriately and effectively. Knowing how to teach does not simply involve knowing how to do things in the classroom. Rather it involves cognitive dimension that connects thought with activity. This conceptual know-how is acquired over time and its interpretations bring about effective classroom practice. Accordingly, novice and experienced teachers using a teacher's handbook guide will find structured and open-ended opportunities to observe classroom teaching and to plan and conduct micro-teaching lessons, all in light of the theory and information discussed in each chapter. They can strengthen their individual approaches to teaching by observing, investigating, discussing ideas, teaching, and then relating these activities to one another.

A teacher's handbook guide must be composed of an introduction, preface, purpose and scope of the book and approaches. To make the teaching-learning process effective and efficient set the stage for the lesson, present the lesson, help student to test ideas and analyze the children's response. A teacher's guide is prepared to provide teachers with guidelines on how to effectively use the learner's material to ensure that learners will attain the expected content and performance standards and the learning competencies that must be attained and developed by the learners which they could manifest through their products and performances. The special features of some teacher's guide are learning outcomes, planning of assessment, planning for teaching learning, summative test, glossary of terms and references and other materials. It provides the teachers with the necessary guide and information to be able to teach the lessons in a more creative, engaging, interactive and effective manner ( $\mathrm{K}$ to 12 Curriculum Guide).

A teacher's guide gives teachers and educators ideas and strategies for using the tool (Riordan, 2016). A teacher guide presents appropriate and sufficient background on the subject, suggests teaching strategies usable by most teachers, provides pre- and post-investigation discussions focusing on concept development, inquiry, and the nature of the subject, recommends additional professional development, and indicates the types of support teachers will need for the instructional materials (Evaluating Teacher's Guide Website). Bruce Brooks' teacher's guide provides a pre-reading activity and classroom discussion questions. The guide also includes an interview with the author, reading skills and strategies, and activities to use across the curriculum. (Asylum for Nightface, What Hearts \& The Moves Make the Man) Tolkien's teacher's guide utilizes the lesson planning resources to examine themes of power, corruption, and responsibility. It also includes a preliminary quiz and printable for vocabulary-building, as well as a guided discussion. There are also cross-curricular enrichment activities and handouts to help students get the most out of Tolkien's text. (The Lord of the Rings, Book One) Some teacher's guide includes act summaries, discussion questions, and extensions intended to further engage students in the classroom.

Some proposed guidelines in the preparation of a learning package that promotes the learner-centered principles and practice. The instructional materials help develop active learning and understanding and the teacher employs contemporary teaching process. Begin the lesson with an activity where students share their prior knowledge. Develop intrinsic motivation in students to learn by providing a problem situation which elicits 
their prior knowledge. Aside from having students apply the concepts in a real life situation at the end; a real life situation should be presented at the start, which provides students a familiar context to the topic. Given resources are examined and determined hoe helpful they are for the students to deepen or change their prior knowledge. Provide divergent or process questions which deal with different ways of showing a solution or demonstrating a skill or answering a question or issue from different perspective. Checkpoints for understanding are provided and, students are encouraged to develop the generalizations by using a graphic organizer. Detailed descriptions of the output are provided procedure to be observed and ways of writing and evaluating the works (e.g portfolio, contents, rubrics, checklists). The level of assessment questions reflect is examined. Teachers also provide process questions that will guide the teacher in classification of particular values.

Several practices and strategies promoting the learner-centered principles compose the feature of teaching resource materials: differentiated learning in mathematics, collaborative learning, technology in the classroom, reading and writing in mathematics, mathematical reasoning and problem solving, values integration and assessment in mathematics. The components of the teaching resource materials are title, objectives, content, reference and the teaching-learning process. The title is specific and, concise and attractive to capture the interest of the reader. The objectives are expressed in term of competencies which are knowledge, skills and attitudes that the learner is expected to acquire at the end of the lesson. Content emphasis is on the processes and skills for learning how to learn rather than the ground of facts and information. It is contextualized to make it sensitive to the learner's environment including culture, technology and instructional practices. The content is delivered employing different media and resources. Information and Communication Technology (ICT), instructional and community resources are utilized to enrich learning.

The teaching-learning process promotes active learning and understanding the learners takes on the role of active seeker of knowledge and meaning while the teacher serves as facilitator of learning, guide on the side not a sage on the stage. The integral parts of the teaching-learning process composed the parts of the instructional procedure of the teaching resource materials promote active learning and understanding. In the teaching-learning process, the teacher employs contemporary processes while the students undergo an active learning process. Learning is assessed using a variety of measures. The goal is to gather information about the learner's progress in holistic terms. Authentic assessment is emphasized to engage students in the application of knowledge and skills learned in the same way that they are used in the real world.

\section{$\underline{\text { Research literature }}$}

Since this study is concerned with the assessment of junior high school localized mathematics modules, specifically in Grade 7 and 9 as well as the difficulties met in utilizing them, the researcher did some research on related studies which were found to be of great importance to the present study. Based on Tolentino's study (2014), the K to 12 basic education programs prepares the learner to acquire the mathematical knowledge, skills and process through critical thinking, problem solving and risk taking. The study identified the problems encountered by mathematics teachers in the implementation of $\mathrm{K}$ to 12 programs. It was revealed in this study that teacher-respondents noted that the learning objectives were attained evidently. The curriculum enabled and allowed schools to localize, indigenize, and enhanced their respective educational and social contexts.

This study focused on the readiness of secondary mathematics teachers in the implementation of $\mathrm{K}$ to 12 basic education programs in area I, Division of Batangas. The study of Bico (2016), dealt at the teacher's level of preparedness in the implementation of the K to 12 programs in San Juan District, Division of Batangas. Respondents were prepared in securing the alignment of seats for every activity in terms of classroom management, used discussion as the medium of teaching in terms of the teaching strategies, applied real objects in teaching in terms of instructional materials, and used oral recitation in terms of assessment and evaluation tools.

According to Flores (2005), younger teachers with longer experience in teaching mathematics showed a highly significant relation with teaching competence, highly significant relation with dedication to teaching, 
highly significant relation with knowledge of subject matter, significant relation to classroom organization and management, significant relation with instructional implementation and significant relation with monitoring student progress and potentials. Generally, personal and professional characteristics do not relate to teaching competencies. Only age and number of years in teaching mathematics appear to be predictors of teaching competencies.

Dino (2000) in his study on scholastic performance came up with the finding that the high relationship was attributed since the teacher respondents had an average of 11 years in the service. They had enough expertise in terms of the mastery of the subject matter and they had awareness on what teaching strategies they would use to better explain and make the lessons understandable to students. While, Portacion's study (2000) identified, the extent of difficulty of the beginning elementary school teachers in lesson planning was less difficult. The respondents had a difficult time in showing Instructional skill as perceived by the beginners in the teaching profession as well as in classroom management. The study revealed that beginning teachers found it difficult to manage the classroom.

Cafirma (2001) conducted a study on the teaching competencies of public elementary schools in Region III. Based on her analysis, she found out that majority of the teacher were very satisfied in their teaching competencies. Furthermore, she found out that the years of teaching experiences of teachers and education qualifications were significantly related to teaching competency. Furthermore, based on the study of Bautista (2011), most of the respondents' value work in terms of communication; love of work and initiative are high; the average mean obtained from the achievement in mathematics of intermediate pupil was rated poor. The professional qualities of mathematics teachers also had significant effect on the achievement in mathematics of intermediate pupils.

In his study, Petingco (2000) noted that the competence of teachers in terms of teaching personality, human relations, and pupil evaluation was very satisfactory. On the other hand, management abilities, punctuality and attendance, community participation and allied services were satisfactory. On the other hand the study of Tajonera (2009), revised that the instructional activities used by teachers in teaching mathematics IV were seatwork, board work, assignments and cooperative learning and group. The modeling activities were useful to teachers as means of introducing mathematical concepts using practical examples which students can understand. These encouraged other teachers to adopt these materials to motivate students' participation in this subject which is often viewed difficult to comprehend. Through modeling activities, students may find the subject interesting, enjoyable and useful. Learning may take place because they know the relevance of what they are doing. More importantly, they will realize the functional and practical use of mathematics as applied to day activities.

The study of Ferrer (2011) revealed that there were seven identified desired learning competencies in general science. The desired learning competencies in topics in general science in public and private secondary schools were attained to a great extent. Based on the study of Añonuevo and Manalo (2010), the five most difficult learning tasks in mathematics on the first grading period as revealed by the researcher made diagnostic test were fractions, number theory, whole numbers, and structure and property of real number system. On the second grading period, the top five most difficult learning tasks were definition, properties and solution of inequalities, simplifying algebraic expressions, laws of exponents, scientific notation, and basic concepts on algebraic expressions and mathematical symbols. On the third grading period, the difficult learning tasks were equation of a line, slope of a line, equation of a line, and rectangular coordinate system. On the fourth grading period, the five most difficult learning tasks were factoring completely, factoring a perfect square trinomial, factoring difference of two squares, factoring sum and difference of two cubes, and factoring by grouping.

In the study of Bagcal (2000), the secondary school teachers described themselves as competent in planning, teaching material/equipment and evaluation, instructional strategies, techniques and/or methods and learner's reinforcement involvement. They perceived themselves as very competent in communication with learners and perceived standard. Further the age and growth of service of secondary school teachers are significantly related 
to their teaching competencies. Almario (2002) also conducted a study in validating Manuals in Mathematics. It was found out that a manual was an effective tool in teaching Mathematics. Moreover, it was found out that instructional materials prepared and developed by the teacher showed significant differences is the performance of the learners. It was recommended that manuals in geometry, measurement, maps, graphs and scales should be created to help further evaluate instructional materials prepared by the teachers and that school should welcome researcher using them as venue of study to encourage researchers.

Villamor (2003) conducted a study in the validation of work-text materials in College Algebra and Chemistry. It was found out that both Mathematics and Chemistry instructors strongly agreed that the worktext the work-text in College Algebra with Chemistry applications was valid and acceptable based on their assessments in terms of objectives, content, language and style used and evaluation of technological advances and psychological aspects of individuals and groups. In belief, they must be imbued with wholesome personality and trained well in reliable institution. It is an accepted fact there are many teachers who cannot be able to mold the youth because themselves need to be given intensive training in the profession to develop positive attitudes and value towards the chosen field of work.

Manangan (2011), in her study, found out that the mathematics professors perceived that the work text-book in technical mathematics was higly acceptable as to objectives, subject matter, clarity and usefulness, language and style and evaluation. The use of work textbook as an instructional material improved the performance level of the freshmen students. In the study of Villasotto (2000), the teachers and the administrators/ coordinators disagreed that the objective, the scope and sequence of the material, the organization and presentation, and the strategies and activities of the SEDP Values Education textbook were valid and useful. It was however agreed upon that the application and evaluation of the textbook were valid and useful.

Based on the study of Alegre (2005), voluminous paper works hinder the teachers' preparation as one of the perceived difficulties of the teachers in teaching Social Studies. Another reason was that the mentor was unaccustomed to use varied teaching strategies or methods in instructional delivery. While, Bueno (2006), in her study, revealed that common problems in teaching math were attitude of students towards mathematics, curriculum, basic foundation and teaching strategy. With the new trend in Mathematics education and the shift from teacher-centered to student-centered learning process, utilization of modules and work-text are encouraged. The teaching learning process is greatly enhanced whenever suitable textbooks are available. Work-text for instance may provide students appropriate learning activities and experience so that learning becomes more productive.

\section{$\underline{\text { Synthesis }}$}

The conceptual and research literature cited provided helpful view points for the development of the study. The conceptual literature covered discussions about $\mathrm{K}$ to 12 mathematics program, qualities of mathematics teachers, localized mathematics learners' module, issues and challenges in $\mathrm{K}$ to 12 mathematics, and development of teacher guide. These correlated readings were found to be necessary in the materialization of the study. For the research literature Tolentino's study is similar to the present one as it encourages the used of localize, indigenize and enhanced curriculum. It is different because it dealt with the readiness of Grade 7 and 8 teachers to $k$ to 12 basic education programs, while this study focused on Grade 7 and 9 mathematics modules.

Another study related to the present study is that of Bico et al. as it pointed out the demographic profile of teachers such as age, highest educational attainment and number of seminars attended in relation to their preparedness in the implementation of K to 12 programs in San Juan District, Division of Batangas. On the other hand, according to Flores only age and number of years in teaching mathematics appear to be predictors of teaching competencies. Its purpose and focused field is different from the present study. Dino's study is also related to the present study as it showed high relationship between the number of years in the service and the teaching strategies used to better explain and make the lessons understandable to students. These findings have been beneficial to the researcher. On the other hand, Portacion's study focused on the difficulty of the beginning 
elementary school teachers in lesson planning, in instructional skill, in the teaching profession, and in classroom management, while this study dealt with the difficulties of secondary mathematics teachers in using localized modules.

The scope of the study of Cafirma was public elementary schools in Region III while the scope of this study was the public secondary schools in the Division of Batangas. Her study was centered on teaching competency while this study focused on localized modules. Bautista studied on the professional qualities of mathematics teachers and their effect on the achievement in mathematics of intermediate pupils while this study figures out the effect of professional qualities on teacher's utilization of localized mathematics modules. Petingco noted the competence of teachers while this study figures out the teachers' competence in the used of localized mathematics modules. Meanwhile, Ferrer's study is also similar to the present as it deals with attaining learning competencies. It differs on the field of specification.

The study of Tajonera is similar to the present study, as his aim was to improve Mathematics instruction and its respondents were teachers. It is different to the present study, as it focused on Mathematics IV. Añonuevo and Manalo's study focused on the difficult learning tasks in Mathematics I while this study focuses on the difficulties met by mathematics teachers in executing the learning tasks to Grade 7 and Grade 9 with localized materials as references. For this reason, the two studies are related but different. Bagcal's study covered the relationship of age and growth of service of secondary school teachers and their teaching competencies but it differed with this study in terms of focus and purpose. This study is similar to Almario's because both dealt on creating textual material that will help teachers in their field. The two differs on the use of the output: the former was for evaluating instructional materials while the latter is a guide in utilizing the localized mathematics modules. Villamor's study is also related to the present study as it dealt with the validation of work-text materials in College Algebra and Chemistry, while the output of the present study is a teacher guide for validated localized mathematics modules.

Manangan's study focused on assessing textbooks in technical mathematics, while this study dealt with assessing the localized mathematics module. This made the studies related but different. The study of Villasotto is also related to the present study as it dealt with the agreeability of teachers and the administrators/ coordinators on the validity of the objective, the scope, the sequence of the material, the organization and presentation, the strategies and activities, the application and the evaluation of the SEDP Values Education textbook while the present study aims to provide those for mathematics. The result of Alegre's study showed the difficulties of teachers of teaching social studies, while this study focused on the difficulties of teachers in using the localized mathematics modules. This inspired the researchers in creating the output of this study. Lastly the study of Bueno revealed the common problems in teaching mathematics as perceived by the students and the teachers. On the other hand, this study revealed the problems encountered by mathematics teachers in using mathematics modules Despite the similarities with other researches, there exists various differences which prove that this study is not a duplicate of their studies.

\section{Theoretical framework}

This research was designed to develop a teacher guide for localized mathematics modules in Grades 7 and 9 , which will enhance the use of the said modules. This will help the teachers to cover the expected learning competencies in junior high school mathematics. The findings of this study would eventually lead to improve the mathematics instruction. This study is anchored on three learning theories: Cultural Deficit Theory, Cultural Difference Theory and Theory of Education of Gowin (1984) as shown in Figure 1.

Cultural deficit theory attributes the academic shortcomings of students to students' home culture and environment whereas cultural difference theories shift focus from the home to differences in language and communication styles between home and school. Recent theories place culture at the center of debates surrounding relevance, relationships and rigor in learning processes. Culturally responsive /relevant/based 
education recognizes cultural gaps between home and school as part of the achievement gap and calls for increased cultural relevance in education to engage, support and empower learners.

Figure 1. Theoretical framework

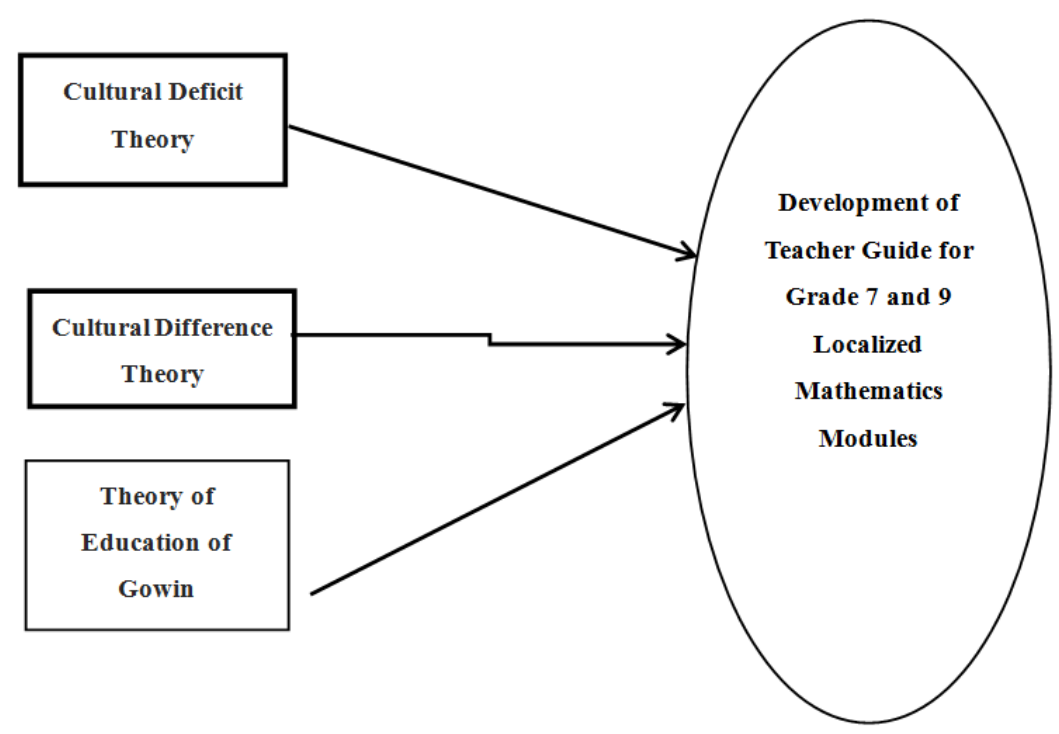

Gowin's Theory focuses on the education event and its related concepts and facts. In an educating event, teachers and learners share meaning and feeling so as to bring about a change in human experiences. This theory stresses the centrality of the learner's experience in education. It states that the theoretical grounding of concept map stems from the assimilation theory whereby, an individual that creates meaningful connection between concepts is better able to learn and use that knowledge than an individual that makes little or no meaningful connections between concepts.

In this theory, the teacher motivates the learners by introducing interesting activities that make students link theories and their life activities and own experiences with follow-up questions. This can contribute to the students' interaction with their teacher, thereby; learners and teachers share their meaningful experiences in life (Novak \& Gowin, 1984). The subject of this study is the localized mathematics module of Grades 7 and 9 which is inspired by cultural deficit theory and cultural difference theory; this helped the researcher in developing the teacher guide. Moreover, the Theory of Education of Gowin led the researcher in relating concepts and linking education to the students' experiences.

\subsection{Conceptual framework}

This study aimed to assess the localized mathematics modules in achieving the learning competencies in Grades 7 and 9 and the difficulties met in the utilization of those materials. It has an end view of developing a teacher guide to help the teachers in using such modules. Based on the theories and several concepts presented, the researcher came up with the conceptual model of the study. This model is one of the tools used by the researcher to ensure the reliability of the study. Hence, the Input-process-Output (IPO) model was utilized. The whole research is shown in figure 2. The design shows the research subject, variables involved, and the result of the study. This gives an overview of what was being targeted by the researcher in the conduct of the study.

In this study, the input as shown in the first box, includes the demographic profile of teachers, localized mathematics modules in Grades 7 and 9, and the difficulties met in the utilization of the localized mathematics modules. The profile of the respondents is grouped according to their gender, highest educational attainment, years of teaching mathematics and mathematics training/ seminar attended. The second box includes the processes that were conducted in the pursuit of this study. This includes gathering of information using interview, questionnaire and analysis of data through appropriate statistical tools. The third box is the teacher guide for the localized mathematics modules in grade 7 and 9 which must be developed to enhance the use of the said 
materials. This teacher guide will be the output of this study.

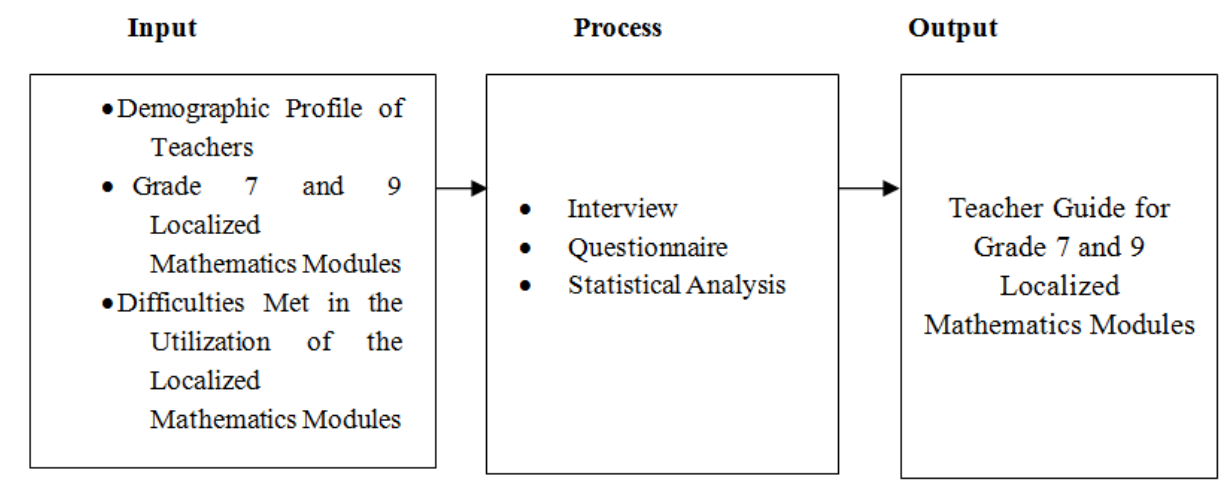

Figure 2. Research paradigm.

\subsection{Definition of terms}

The following terms are utilized throughout the study. For clarification and better understanding, they were defined conceptually and operationally.

Learning Competencies. Learning competencies are lists of competencies which are used in education to describe education goals - the abilities and skills a student should learn in an educational program. In this study, it referred on the specific learning competencies prescribed by the DepEd for Grades 7 and 9 mathematics.

Learning Difficulties. Learning difficulties are lists of difficulties which are encountered by teachers in education. In this study, it refers on the difficulties met by Grades 7 and 9 mathematics teachers in the utilization of the localized mathematics modules.

Localized Module. Localized module is the material that adapts and relates the content of the curriculum and the process of teaching and learning to local conditions, environments, and resources. In this study, it was used as the prescribed material in mathematics that needs a teacher guide.

Teacher Guide. Teacher guide provides guidelines on how to effectively use the learner's material to ensure that learners will attain the expected content and performance standards.. A teacher guide serves as the output of the study.

\section{Research method and procedure}

This part presents the research design, the subject of the study, the data gathering instrument, the data gathering procedure and the statistical treatment of data.

\subsection{Research design}

This study utilized the descriptive method of research. This method of research is the most appropriate to use since it involves looking into the present situation and describing it using quantitative measurements. It is the most common methodology because it summarizes the characteristics of individuals or groups or physical environments such as schools. For the purpose of this study, the researcher designed a questionnaire to meet the specific goals of this research endeavor, the result which were analyzed statistically with appropriate tools.

\subsection{Subject of the study}

The population of Grades 7 and 9 mathematics teachers in the national high schools of the Division of Batangas is 338, with 177 Grade 7 mathematics teachers and 161 Grade 9 mathematics teachers. The researcher 
Development of teacher guide for Grade 7 and 9 localized mathematics modules

used the Slovin's formula to get the total number of sample per grade level. The distribution of Grade 7 and 9 mathematics teacher-respondents by area is shown in Table 1 and 2. In this study, 123 Grade 7 teachers and 115 Grade 9 teachers served as respondents.

Table 1

Distribution of grade 7 mathematics teachers in the division of Batangas

\begin{tabular}{ccc}
\hline Area & Population & Sample \\
\hline I & 61 & 42 \\
II & 31 & 21 \\
III & 33 & 23 \\
IV & 52 & 36 \\
TOTAL & 177 & 123 \\
\hline
\end{tabular}

\section{Table 2}

Distribution of grade 9 mathematics teachers in the division of Batangas

\begin{tabular}{ccc}
\hline Area & Population & Sample \\
\hline I & 55 & 39 \\
II & 30 & 21 \\
III & 29 & 21 \\
IV & 47 & 34 \\
TOTAL & 161 & 115 \\
\hline
\end{tabular}

\subsection{Data gathering instrument}

The researcher gathered information from books, unpublished theses, general references, magazines/journals and websites in the field of education and mathematics teaching. The main instrument in gathering data was the researcher-made questionnaire while underwent the process of construction, validation, administration and scoring of responses.

Construction. The researcher, together with Ms. Bautista, prepared a questionnaire based on the survey they conducted on the difficulties met by mathematics teachers in the utilization of localized mathematics modules. They compiled the gathered information and used it to substantiate the questionnaires. The draft of the questionnaires was presented to the adviser for corrections and suggestions. After the revision of the instrument, the revised draft was made. It was presented again to the adviser for further suggestions. Corrections were again incorporated until the final draft was created.

Validation. After preparing the revised questionnaires, the items were presented to the panel. They gave suggestions for further revisions and improvements. They sought the help of their adviser as to which suggestions to incorporate for those that have contradicting comments. Suggestions were incorporated and the revised draft was developed. Then, the final draft was subjected to a dry run. The participants were mostly the graduate students of Batangas State University. Cronbach alpha of 0.85 was computed to determine the reliability of the items in the questionnaire, since it is greater than 0.7 . The items were found to have good internal consistency and were reliable.

Administration. The final draft of the questionnaires was produced for the administration to the target respondents. The researchers sought the help of the Mathematics Education Program Supervisor, Mrs. Elizabeth Tolentino who sent the questionnaire to different schools in the Division of Batangas. The respondents sent the accomplished questionnaires on the website created by the researcher solely for the purpose of this study.

Scoring. To interpret the assessment of the localized mathematics modules in achieving the learning competencies by grade level, the following scale was used: 


\begin{tabular}{c|c}
\hline Range & Interpretation \\
\hline $3.25-4.00$ & Very Satisfactory \\
\hline $2.50-3.24$ & Satisfactory \\
\hline $1.75-2.49$ & Poor \\
\hline $1.00-1.74$ & Not Satisfactory \\
\hline
\end{tabular}

\subsection{Data gathering procedure}

At the outset of the study, the researcher, together with Ms. Bautista engaged in gathering information related to the research variables. The body of information that was gathered provided by with additional insights as to the instrument to be used in gathering data. The researcher prepared a letter of request for the conduct of the study and sent it to the Division's Office of Batangas. Upon approval of the request, the researchers sought the help of the Mathematics Educational Program Supervisor (EPS) in administering the questionnaire. The EPS sent the questionnaires to all schools in the Division of Batangas through an e-mail. The said material contained instructions for easy and systematic retrieval. Some of the schools failed to submit their answers on time still, the number of respondents who passed their assessments was enough to fill in the sample size. The researchers tabulated the data for statistical treatment while still waiting for the other school's responses. The findings were extracted and analyzed based on the processed data.

\subsection{Statistical treatment}

In order to interpret the data gathered, the following statistical tools were used.

Analysis of Variance (ANOVA). This was used to compute the significant differences on the assessments on the localized mathematics modules when teachers are grouped according to highest educational attainment, years of teaching mathematics, and mathematics training/seminars attended.

Frequency. This was used to determine the number of responses on the questionnaires given.

Mean. This was used to determine the frequency of the respondents' responses.

Percentage. This was used to determine the part of the number of the respondents from the entire sample population.

Independent sample T-Test. This was used to compute the significant difference on the assessments of the localized mathematics modules teachers are grouped according to gender.

\section{Presentation, analysis and interpretation}

This part covers the presentation, analysis and interpretation of the quantitative data gathered in the investigation. The discussions of the findings are patterned in a manner that has equivalence with the organization of the problems posed in the study.

\subsection{Profile of grade 7 ad 9 mathematics teachers}

The profile of the respondents in terms of gender, highest educational attainment, years of teaching mathematics and mathematics trainings/seminars attended and tabulated in Tables 3 to 6 . Table 3 presents the profile of Grades 7 and 9 mathematics teachers in terms gender. Based on Table 3, 48 out of 238 teachers or $20.17 \%$ are male and 190 out of 238 teachers or $79.83 \%$ are female. It can be deduced that most of the teachers in the Division of Batangas are female. It is an apparent reality that majority of professionals who are inclined in teaching profession are female which supports Tolentino' study that revealed that many mathematics teachers are 
female because teaching profession is dominated by women.

\section{Table 3}

Distribution of grades 7 and 9 mathematics teachers in terms of gender

\begin{tabular}{lcccc}
\hline \multicolumn{1}{c}{ Gender } & Grade 7 & Grade 9 & TOTAL & $\%$ \\
\hline Male & 20 & 28 & 48 & 20.17 \\
Female & 103 & 87 & 190 & 79.83 \\
\multicolumn{1}{c}{ TOTAL } & 123 & 115 & 238 & 100.00 \\
\hline
\end{tabular}

\section{Table 4}

Distribution of grades 7 and 9 mathematics teachers in terms of highest educational attainment

\begin{tabular}{|c|c|c|c|c|}
\hline Highest Educational Attainment & Grade 7 & Grade 9 & TOTAL & $\%$ \\
\hline Doctorate Degree & 0 & 0 & 0 & 0.00 \\
\hline With Doctorate units & 1 & 3 & 4 & 1.68 \\
\hline Master's Degree & 22 & 9 & 31 & 13.03 \\
\hline With Master's units & 65 & 70 & 135 & 56.72 \\
\hline Baccalaureate Degree & 35 & 33 & 68 & 28.57 \\
\hline TOTAL & 123 & 115 & 238 & 100.0 \\
\hline
\end{tabular}

Based on Table 4, no teacher out of 238 respondents is a doctorate degree holder, while 4 out of 238 teachers or $1.68 \%$ have doctorate units, 31 teachers or $13.03 \%$ are master's degree holders, 135 respondents or $56.72 \%$ have master's units, and 68 out of 238 teachers or $28.57 \%$ are baccalaureate degree holders. It can be seen in the data that majority of Grades 7 and 9 mathematics teachers already have units in their master's degree, which means that they strive to continue further studies for their professional development. This shows improvement from the study of Bico et al. which showed that majority of teachers only has a bachelor's degree. This also means that majority of the mathematics teachers understand the importance of engaging in graduate studies for continuous personal and professional advancement.

Years of Teaching Mathematics. Table 5 presents the profile of the respondents in terms of years of teaching mathematics.

Based on Table 5, 10 out of 238 teachers or $4.20 \%$ have 31 years or more years of teaching mathematics, while 12 or $5.04 \%$ have 26 to 30 years of teaching, 19 teachers or $7.98 \%$ have 21 to 25 years of teaching, 28 teachers or $11.77 \%$ have 16 to 20 years of teaching, 28 teachers or $11.77 \%$ have 11 to 15 years of teaching, 33 teachers or $13.87 \%$ have $6-10$ years of teaching, and majority of 114 teachers or $50.7 \%$ have at most 5 years of teaching mathematics.

\section{Table 5}

Distribution of the grades 7 and 9 mathematics teachers in terms of years of teaching mathematics

\begin{tabular}{|c|c|c|c|c|}
\hline Years of Teaching Mathematics & Grade 7 & Grade 9 & TOTAL & $\%$ \\
\hline 31 or more & 0 & 10 & 10 & 4.20 \\
\hline $26-30$ & 8 & 4 & 12 & 5.04 \\
\hline $21-25$ & 9 & 10 & 19 & 7.98 \\
\hline $16-20$ & 8 & 14 & 22 & 9.24 \\
\hline $11-15$ & 10 & 18 & 28 & 11.77 \\
\hline $6-10$ & 19 & 14 & 33 & 13.87 \\
\hline $0-5$ & 69 & 45 & 114 & 47.90 \\
\hline TOTAL & 123 & 115 & 238 & 100.00 \\
\hline
\end{tabular}

It can be noted in the findings that most of the Grades 7 and 9 mathematics teachers are relatively new in the teaching profession. It can be inferred that the reason why the respondents find difficulties in utilizing the localized mathematics modules was their lack of teaching experience, especially since almost half of them have less five years of professional experience in the field of teaching. 
This supports Tolentino's study that mathematics teachers who are teaching for more than 3 decades are considered as experienced teachers, and they are already aware of the concepts and skills which the student find difficult. This is also sustained in Dino's study revealing that the teacher respondents who have an average of 11 years in the service have enough expertise in terms of the mastery of the subject matter, plus they have awareness on what teaching strategy they should use to better explain and make the lesson understandable to students.

Mathematics Training/ Seminars Attended. Table 6 presents the profile of the respondents in terms of mathematics training/seminars attended.

Table 6

Distribution of grade 7 and 9 mathematics teachers in terms of participation to trainings/seminars

\begin{tabular}{|c|c|c|c|c|}
\hline Participation to Trainings/Seminars & Grade 7 & Grade 9 & TOTAL & $\%$ \\
\hline Very Active & 0 & 0 & 0 & 0.00 \\
\hline Active & 3 & 10 & 13 & 5.46 \\
\hline Moderately Active & 18 & 34 & 52 & 21.85 \\
\hline Not Active & 102 & 71 & 173 & 72.69 \\
\hline TOTAL & 123 & 115 & 238 & 100.00 \\
\hline
\end{tabular}

Based on Table 6, no teacher has been very actively participating in trainings and seminars for the last four years, and only 13 out of 238 teachers or $5.46 \%$ are actively participating. A total of 52 teachers or $21.85 \%$ are moderately participating, while the majority or 173 teachers or $72.69 \%$ are not actively participating in trainings and seminars in mathematics for the last four years. This contradicts the study of Tolentino, which found out that Grades 7 and 8 mathematics teachers in the public schools were given the opportunity to attend mass training conducted by DepEd for free.

It is somehow alarming that majority of the Grades 7 and 9 mathematics teachers in the Division of Batangas are not active in attending trainings/seminars. This may have an effect on the difficulties they encountered in using localized modules. Not only are they lacking in teaching experience, they also lack proper training and skills development opportunities.

\subsection{Teachers'assessment of the localized mathematics modules in achieving learning competencies}

This section shows the assessments of the teachers on the localized mathematics module in achieving the learning competencies of Grades 7 and 9. Table 7 shows the teachers' assessment of the Grade 7 mathematics module.

Table 7

Teachers' assessment of the grade 7 localized mathematics module

\begin{tabular}{|c|c|c|}
\hline Factors & Mean & Interpretation \\
\hline 1.Content & 2.99 & Satisfactory \\
\hline 2.1.Formats - Prints & 3.08 & Satisfactory \\
\hline 2.2.Formats - Illustrations & 2.99 & Satisfactory \\
\hline 2.3.Formats - Design and Layout & 3.02 & Satisfactory \\
\hline 3.Presentation and Organization & 2.96 & Satisfactory \\
\hline 4.Accuracy and Up-to-Date Information & 2.62 & Satisfactory \\
\hline Composite Mean & 2.94 & Satisfactory \\
\hline
\end{tabular}

Based on the table, the composite mean of 2.94 indicates that the Grade 7 localized mathematics module, as assessed by the 123 teachers, satisfactorily conformed to the module/instructional materials evaluation criteria in terms of content, format, presentation and organization, and accuracy and up-to-date information. This implies that the use of the localized module for Grade 7 mathematics can more likely achieve the required learning competencies in the grade level. 
Development of teacher guide for Grade 7 and 9 localized mathematics modules

Table 8

Teachers' assessment of the grade 9 localized mathematics module

\begin{tabular}{|c|c|c|}
\hline Factors & Mean & Interpretation \\
\hline 1.Content & 3.07 & Satisfactory \\
\hline 2.1.Formats - Prints & 3.18 & Satisfactory \\
\hline 2.2.Formats - Illustrations & 3.01 & Satisfactory \\
\hline 2.3.Formats - Design and Layout & 3.01 & Satisfactory \\
\hline 3.Presentation and Organization & 2.99 & Satisfactory \\
\hline \multirow[t]{2}{*}{ 4.Accuracy and Up-to-Date Information } & 2.53 & Satisfactory \\
\hline & 2.97 & Satisfactory \\
\hline
\end{tabular}

Based on the table, composite mean of 2.97 indicates that the Grade 9 localized mathematics module, as assessed by the 115 teachers, also satisfactorily conformed to the module/instructional materials evaluation criteria in terms of content, format, presentation and organization, and accuracy and up-to-date information. This implies that the use of the localized module for Grade 9 mathematics can more likely achieve the required learning competencies of grade level.

These results the study of Villamor, that the work text in college algebra with chemistry application was valid and acceptable based on their assessments in terms of objectives, content, language and style use and evaluation of technological advances and psychological aspects of individuals and groups. It is accepted fact that for instructional materials to be effective, these have to possess accurate content, appropriate print and layout, organized presentation, and updated information to successfully aid the teaching-learning process.

\subsection{Differences on the assessments when grouped according to profile variables}

One of the purposes of this study was to test the significant differences on the respondent's assessment on the localized modules. The difference on the assessments of the localized mathematics modules when respondents are grouped according to gender was revealed using T-test, while the difference on the assessments of the localized mathematics modules when respondents are grouped according to highest educational attainment, years of teaching mathematics and mathematics training/seminars attended was revealed using ANOVA.

\section{Table 9}

Differences on the teachers' assessment according to gender

\begin{tabular}{lcccc}
\hline \multicolumn{1}{c}{ Factors } & $t$-value & $p$-value & Decision on Ho & Interpretation \\
\hline 1.Content & 3.722 & .000 & Reject & Significant \\
2.1Formats - Prints & 0.874 & .384 & Failed to Reject & Not Significant \\
2.2.Formats - Illustrations & 4.011 & .000 & Reject & Significant \\
2.3.Formats - Design and Layout & 1.930 & .056 & Failed to Reject & Not Significant \\
3.Presentation and Organization & 4.367 & .000 & Reject & Significant \\
4.Accuracy and Up-to-Date Information & 2.481 & .014 & Reject & Significant \\
\hline
\end{tabular}

Based on the table, the computed $t$-value of $3.722,4.011,4.367$, and 2.481 with a $p$-value of $.000, .000, .000$, and $.014(<.05)$, respectively, indicates that the null hypothesis is rejected. This means that there is a significant difference on the assessments on the content, illustrations, presentation and organization, and accuracy and up-to-date information of Grade 7 localized mathematics module when teachers are grouped according to gender. Male and female teachers were found to have different assessments of the content, illustrations, presentation and organization, and accuracy and up-to-date information of Grade 7 localized mathematics module.

On the other hand, the computed $t$-value of 0.874 and 1.930 with a $p$-value of .384 and $.056(>.05)$, respectively, indicates that the null hypothesis is not rejected. This means that there is no significant difference on the assessments of the prints and design and lay-out of Grade 7 localized mathematics module when teachers are grouped according to gender. Male and female teachers were found to have similar assessments on the prints and design and lay-out of Grade 7 localized mathematics module. 
Panopio, J.

Table 10

Differences on the teachers' assessment according to their highest educational attainment

\begin{tabular}{lcccc}
\hline \multicolumn{1}{c}{ Factors } & $F$-value & $p$-value & Decision on Ho & Interpretation \\
\hline 1.Content & 2.594 & .056 & Failed to Reject & Not Significant \\
2.1Formats - Prints & 2.754 & .046 & Reject & Significant \\
2.2.Formats - Illustrations & 1.843 & .143 & Failed to Reject & Not Significant \\
2.3.Formats - Design and Layout & 2.555 & .059 & Failed to Reject & Not Significant \\
3.Presentation and Organization & 0.581 & .629 & Failed to Reject & Not Significant \\
4.Accuracy and Up-to-Date Information & 1.561 & .203 & Failed to Reject & Not Significant \\
\hline
\end{tabular}

Based on the table, the computed $F$-values of $2.594,1.843,2.555,0.581$ and 1.561 with $p$-value of $.056, .143, .059, .629$, and $.203(>.05)$, respectively, indicate that the null hypothesis is not rejected. This means that there is no significant difference on the assessments on the content, illustrations, designs and layout, presentation and organization and accuracy and up-to-date information of Grade 7 localized mathematics module when teachers are grouped according to their highest educational attainment. Even if teachers have different educational profiles, they still had a similar assessment of the Grade 7 localized mathematics module relative to the evaluation criteria.

The computed $F$-value of 2.754 with a $p$-value of $.046(<.05)$ indicates that the null hypothesis is rejected. This means that there is a significant difference on the assessments on the print-out of Grade 7 localized mathematics module when teachers are grouped according to their highest educational attainment. Teachers with different educational profiles have different assessments on the print out of Grade 7 localized mathematics module. Teachers with doctorate units had a more stringent and critical evaluation of the module probably because of their vast experience in the field.

\section{Table 11}

Differences on the teachers' assessment according to their years of teaching mathematics

\begin{tabular}{lcccc}
\hline \multicolumn{1}{c}{ Factors } & $F$-value & $p$-value & Decision on Ho & Interpretation \\
\hline 1.Content & 5.358 & .000 & Reject & Significant \\
2.1Formats - Prints & 0.824 & .535 & Failed to Reject & Not Significant \\
2.2.Formats - Illustrations & 6.307 & .000 & Reject & Significant \\
2.3.Formats - Design and Layout & 8.294 & .000 & Reject & Significant \\
3.Presentation and Organization & 4.457 & .001 & Reject & Significant \\
4.Accuracy and Up-to-Date Information & 5.673 & .000 & Reject & Significant \\
\hline
\end{tabular}

Table 11 presents the differences on the teachers' assessment on the Grade 7 localized mathematics module when grouped according to their years of teaching mathematics. Based on Table 11, the computed $F$-values of $5.358,6.307,8.295,4.457$, and 5.673 with $p$-value of $.000, .000, .000, .001$, and .000 (<.05), respectively, indicate that the null hypothesis is rejected. This means that there is a significant difference on the assessments of the content, illustrations, design and lay-out, presentation and organization, and accuracy and up-to-date information of Grade 7 localized mathematics module when teachers are grouped according to their years of teaching mathematics. Teachers with varying years of teaching experience to have different assessments on the content, illustrations, design and lay-out, presentation and organization and accuracy and up-to-date information of the module. Teachers with extensive experience in teaching mathematics assessed the module with more objectivity and analysis based on the evaluation criteria.

The computed $F$-value of 0.824 with a $p$-value of .535 (>.05) indicates that the null hypothesis is not rejected. This means that there is no significant difference on the assessments on the print-out of Grade 7 localized mathematics module when teachers are grouped according to their years of teaching mathematics. Even if teachers have various teaching experiences they have similar assessments of Grade 7 localized mathematics module in terms of the way it was printed. 
Development of teacher guide for Grade 7 and 9 localized mathematics modules

Table 12

Differences on the teachers' assessment according to their participation in trainings and seminars

\begin{tabular}{lcccc}
\hline \multicolumn{1}{c}{ Factors } & $F$-value & $p$-value & Decision on Ho & Interpretation \\
\hline 1.Content & 0.071 & 0.932 & Failed to Reject & Not Significant \\
2.1Formats - Prints & 1.177 & 0.312 & Failed to Reject & Not Significant \\
2.2.Formats - Illustrations & 0.388 & 0.679 & Failed to Reject & Not Significant \\
2.3.Formats - Design and Layout & 0.543 & 0.583 & Failed to Reject & Not Significant \\
3.Presentation and Organization & 1.172 & 0.313 & Failed to Reject & Not Significant \\
4.Accuracy and Up-to-Date Information & 6.097 & 0.003 & Reject & Significant \\
\hline
\end{tabular}

Based on Table 12, the computed $F$-values of $0.071,1.177,0.388,0.543$, and 1.172 with $p$-value of $.932, .312, .679, .583$, and $.313(>.05)$, respectively, indicate that the null hypothesis is not rejected. This means that there is no significant difference on the assessments on the content, prints, illustrations, design and layout, and presentation and organization of Grade 7 localized mathematics module when teachers are grouped according to their participation to trainings and seminars. Teachers with varying degrees of active participation to trainings and seminars are having similar assessments of the module based on the evaluation criteria.

The computed $F$-value of 6.097 with a $p$-value of $.003(<.05)$ indicates that the null hypothesis is rejected. This means that there is a significant difference on the assessments on the accuracy and up-to-date information of Grade 7 localized mathematics module when teachers are grouped according to their participation to trainings and seminars. Teachers with varying degrees of participation to trainings and seminars have different assessments on the accuracy and up-to-date information presented in the Grade 7 localized mathematics module. Teachers who actively participated in trainings and seminars assessed the module more objectivily because of their exposure to updated information regarding the subject.

\section{Table 13}

Differences on the teachers' assessments according to gender

\begin{tabular}{lcccc}
\hline \multicolumn{1}{c}{ Factors } & $t$-value & $p$-value & Decision on Ho & Interpretation \\
\hline 1.Content & 0.900 & .370 & Failed to Reject & Not Significant \\
2.1Formats - Prints & 2.531 & .013 & Reject & Significant \\
2.2.Formats - Illustrations & 1.8656 & .065 & Failed to Reject & Not Significant \\
2.3.Formats - Design and Layout & 1.421 & .158 & Failed to Reject & Not Significant \\
3.Presentation and Organization & 0.807 & .421 & Failed to Reject & Not Significant \\
4.Accuracy and Up-to-Date Information & 1.373 & .173 & Failed to Reject & Not Significant \\
\hline
\end{tabular}

Based on table, the Grade 9 localized mathematics module as assessed by the 115 teachers, conformed to the module/instructional materials evaluation criteria in terms of content, format, presentation and organization and accuracy and up-to-date information. In terms of gender, the computed $t$-value of 2.531 with a $p$-value of .013 $(<.05)$ indicates that the null hypothesis is rejected. This means that there is a significant difference on the assessments on the prints of Grade 9 localized mathematics module when teachers are grouped according to gender.

The computed $t$-values of $0.900,1.8656,1.421,0.807$ and 1.373 with p-value of $.370, .065, .158, .421$, and .173 (>.05), respectively, indicate that the null hypothesis is not rejected. This means that there is no significant difference on the assessment of the content, illustrations, design and lay-out, presentation and organization, and accuracy and up-to-date information of Grade 9 localized mathematics module when teachers are grouped according to gender. Male and female teachers have similar assessments on the module based on the evaluation criteria.

As for Table 14 , the computed $F$-values of $2.178,0.958$, and 2.530 with $p$-values of $.095, .415$, and .061 (>.05), respectively, indicate that the null hypothesis is not rejected. This means that there is no significant difference on the assessments on the content, prints, and presentation and organization of Grade 9 localized mathematics module when teachers are grouped according to their highest educational attainment. Even if 
Panopio, J.

teachers have different educational attainment they have similar assessments in terms of the aforementioned evaluation criteria.

\section{Table 14}

Differences on the teachers' assessment according to highest educational attainment

\begin{tabular}{lcccc}
\hline \multicolumn{1}{c}{ Factors } & $F$-value & $p$-value & Decision on Ho & Interpretation \\
\hline 1.Content & 2.178 & .095 & Failed to Reject & Not Significant \\
2.1Formats - Prints & 0.958 & .415 & Failed to Reject & Not Significant \\
2.2.Formats - Illustrations & 5.580 & .001 & Reject & Significant \\
2.3.Formats - Design and Layout & 9.077 & .000 & Reject & Significant \\
3.Presentation and Organization & 2.530 & .061 & Failed to Reject & Not Significant \\
4.Accuracy and Up-to-Date Information & 5.576 & .001 & Reject & Significant \\
\hline
\end{tabular}

The computed $F$-values of 5.580, 9.077 and 5.576 with $p$-values of .001, .000, and .0001 (<.05), respectively, indicate that the null hypothesis is rejected. This means that there is a significant difference on the assessment of the illustrations, design and layout and accuracy and up-to-date information of Grade 9 localized mathematics module when teachers are grouped according to their highest educational attainment. Teachers with different educational attainments have different assessments the module based on the aforementioned criteria. Teachers with doctorate units may have assessed more stringently the illustrations, design and layout and accuracy and up-to-date information of the module.

\section{Table 15}

Differences on the teachers' assessment according to years of teaching mathematics

\begin{tabular}{lcccc}
\hline \multicolumn{1}{c}{ Factors } & $F$-value & $p$-value & Decision on Ho & Interpretation \\
\hline 1.Content & 2.931 & .011 & Reject & Significant \\
2.1Formats - Prints & 0.462 & .835 & Failed to Reject & Not Significant \\
2.2.Formats - Illustrations & 0.291 & .940 & Failed to Reject & Not Significant \\
2.3.Formats - Design and Layout & 2.018 & .069 & Failed to Reject & Not Significant \\
3.Presentation and Organization & 1.930 & .082 & Failed to Reject & Not Significant \\
4.Accuracy and Up-to-Date Information & 1.504 & .165 & Failed to Reject & Not Significant \\
\hline
\end{tabular}

Based on table, the computed $F$-value of 2.931 with a $p$-value of $.011(<.05)$ indicates that the null hypothesis is rejected. This means that there is a significant difference on the assessments on the content of Grade 9 localized mathematics module when teachers are grouped according to their years of teaching mathematics. Teachers with varying years of teaching mathematics had different assessment of the content of Grade 9 localized mathematics module. Teachers with more years of teaching mathematics are more likely to assess more objectively the content of the module. The computed $F$-values of $0.462,0.291,2.018,1.930$, and 1.504 with $p$-values of $.835, .940, .069, .082$, and $.165,(>.05)$ respectively, indicate that the null hypothesis is not rejected. This means that there is no significant difference on the assessments of the prints, illustrations, design and layout, presentation and organization and accuracy and up-to-date information of Grade 9 localized mathematics module when teachers are grouped according to their years of teaching mathematics. Even if teachers varied in their years of teaching experience they had similar assessments on the aforementioned evaluation criteria.

\section{Table 16}

Differences on the teachers' assessment according to participation to trainings and seminars

\begin{tabular}{lcccc}
\hline \multicolumn{1}{c}{ Factors } & $F$-value & $p$-value & Decision on Ho & Interpretation \\
\hline 1.Content & 0.774 & .463 & Failed to Reject & Not Significant \\
2.1Formats - Prints & 1.129 & .327 & Failed to Reject & Not Significant \\
2.2.Formats - Illustrations & 0.271 & .763 & Failed to Reject & Not Significant \\
2.3.Formats - Design and Layout & 1.130 & .327 & Failed to Reject & Not Significant \\
3.Presentation and Organization & 1.998 & .140 & Failed to Reject & Not Significant \\
4.Accuracy and Up-to-Date Information & 0.673 & .512 & Failed to Reject & Not Significant \\
\hline
\end{tabular}

50 Consortia Academia Publishing (A partner of Network of Professional Researchers and Educators) 
Based on table, the computed F-values of $0.774,1.129,0.271,1.130,1.998$, and 0.673 with $p$-values of $.463, .327, .763, .327, .140, .512(>0.05)$, respectively, indicate that the null hypothesis is not rejected. This means that there is no significant difference on the assessments on all the factors of Grade 9 localized mathematics module when teachers are grouped according to their participation to trainings and seminars. Teachers with varying degrees of participation to trainings and seminars had similar assessment of all the factors of the Grade 9 localized mathematics module.

\subsection{Difficulties met in the utilization of the localized learners' mathematics modules}

In this part of the study, the difficulties met in the utilization of the localized mathematics modules are discussed. Specifically, Grades 7 and 9 mathematics teachers identified the difficulties that they encountered in the use of the localized mathematics modules.

\section{Table 17}

Difficulties met in the utilization of grade 7 localized mathematics module

\begin{tabular}{|c|c|c|c|}
\hline Difficulties & Mean & Interpretation & Rank \\
\hline $\begin{array}{l}\text { 1. The contents in the module are difficult to match with the format of the } \\
\text { new daily learning } \log (\mathrm{DLL}) \text {. }\end{array}$ & 2.42 & Disagree & 13 \\
\hline 2. The localized module requires extra planning-time for teachers. & 2.56 & Agree & 10.5 \\
\hline 3. The objectives in the localized module are broad. & 2.34 & Disagree & 15 \\
\hline 4. The real-life application of the lessons is not clearly stated. & 2.56 & Agree & 10.5 \\
\hline 5. The students do not have printed localized mathematics module. & 3.22 & Agree & 1 \\
\hline $\begin{array}{l}\text { 6. There are activities which are not suitable to mentally challenged } \\
\text { learners. }\end{array}$ & 2.46 & Disagree & 12 \\
\hline 7. There are activities which are time-consuming. & 2.81 & Agree & 5 \\
\hline 8. There are grammatical errors. & 2.63 & Agree & 8 \\
\hline 9. There are no answer keys for each activity and evaluation. & 2.99 & Agree & 2 \\
\hline 10. There are no suggested strategies. & 2.92 & Agree & 3 \\
\hline $\begin{array}{l}\text { 11. There are no teaching procedures that indicate what to do and when } \\
\text { to do it. }\end{array}$ & 2.80 & Agree & 6 \\
\hline $\begin{array}{l}\text { 12. There are some learning competencies which fail to be covered due to } \\
\text { limited time. }\end{array}$ & 2.82 & Agree & 4 \\
\hline 13. There are terminologies which are not-easy to understand. & 2.37 & Disagree & 14 \\
\hline 14. There is no consistency of format of the text. & 2.58 & Agree & 9 \\
\hline 15. There is no given approach to easily execute the lesson. & 2.67 & Agree & 7 \\
\hline Composite Mean & 2.68 & Agree & \\
\hline
\end{tabular}

As can be seen in the table, the composite mean of 2.68 indicates the Grade 7 teachers' agreement that they met some difficulties in the utilization of Grade 7 localized mathematics module. Out of the 15 difficulties listed by the researchers, the teachers agreed on 11 statements. Students do not have printed localized mathematics module, there are no answer keys for each activity and evaluation, and there are no suggested strategies for lesson delivery. These three have the highest weighted mean of 3.22, 2.99 and 2.92, respectively.

On the other hand, the Grade 7 teachers disagreed on some statements such as the objectives of the module being broad and there are terminologies which are not easy to understand. These two have composite means of 2.34 and 2.32, respectively. The teachers also disagreed that the content of the module being difficult to match with the format of the new DLL and some activities are not suitable to mentally challenged learners with composite means of 2.42 and 2.46, respectively. It is quite apparent that grade 7 mathematics teachers are in need of a teacher guide in utilizing the localized module. This guide must provide answer keys and suggested strategies to cover the required learning competencies in the subject. 
Table 18

Difficulties met in the utilization of grade 9 localized mathematics module

\begin{tabular}{|c|c|c|c|}
\hline Difficulties & Mean & Interpretation & Rank \\
\hline $\begin{array}{l}\text { 1. The contents in the module are difficult to match with the } \\
\text { format of the new daily learning log (DLL). }\end{array}$ & 2.34 & Disagree & 10 \\
\hline $\begin{array}{l}\text { 2. The localized module requires extra planning-time for } \\
\text { teachers. }\end{array}$ & 2.33 & Disagree & 11 \\
\hline 3. The objectives in the localized module are broad. & 2.10 & Disagree & 15 \\
\hline 4. The real-life application of the lessons is not clearly stated. & 2.27 & Disagree & 12.5 \\
\hline $\begin{array}{l}\text { 5. The students do not have printed localized mathematics } \\
\text { module. }\end{array}$ & 2.83 & Agree & 2 \\
\hline $\begin{array}{l}\text { 6. There are activities which are not suitable to mentally } \\
\text { challenged learners. }\end{array}$ & 2.50 & Agree & 8 \\
\hline 7. There are activities which are time-consuming. & 2.77 & Agree & 3 \\
\hline 8. There are grammatical errors. & 2.36 & Disagree & 9 \\
\hline 9. There are no answer keys for each activity and evaluation. & 2.92 & Agree & 1 \\
\hline 10. There are no suggested strategies. & 2.75 & Agree & 4 \\
\hline $\begin{array}{l}\text { 11. There are no teaching procedures that indicate what to do } \\
\text { and when to do it. }\end{array}$ & 2.73 & Agree & 5 \\
\hline $\begin{array}{l}\text { 12. There are some learning competencies which fail to be } \\
\text { covered due to limited time. }\end{array}$ & 2.51 & Agree & 7 \\
\hline 13. There are terminologies which are not-easy to understand. & 2.27 & Disagree & 12.5 \\
\hline 14. There is no consistency of format of the text. & 2.24 & Disagree & 14 \\
\hline 15. There is no given approach to easily execute the lesson. & 2.52 & Agree & 6 \\
\hline Composite Mean & 2.50 & Agree & \\
\hline
\end{tabular}

Based on the table, the composite mean of 2.50 indicates that the Grade 9 teachers generally agreed that they met some difficulties in the utilization of Grade 9 localized mathematics module. Out of the 15 difficulties mentioned by the researchers, Grade 9 teachers agreed on eight items. There are no answer keys for each activity and evaluation, the students do not have printed localized mathematics module, and there are activities which are time consuming rank first, second and third, with composite means of 2.92, 2.83 and 2.77, respectively.

On the other hand, the respondents disagreed on seven statements on the list the objectives in the module are broad and there is no consistency of text format ranked $14^{\text {th }}$ and $15^{\text {th }}$ with composite means of 2.10 and 2.24 , respectively. From the result it is clear that, grade 9 mathematics teachers are in need of a teacher guide in utilizing the localized module. This must have answer key and suggested strategies to cover the required learning competencies within the prescribed time frame.

\subsection{Teacher guide for the enhancement of mathematics teaching and learning}

From the analysis of the gathered data, it was revealed that there is a need to develop a teacher guide for the localized modules to enhance mathematics teaching and learning. Hence a teacher's guide was prepared to provide teachers with information and guidelines on how to effectively use the prescribed materials to ensure that learners will attain the expected content and performance standards. The learning competencies that must be acquired and developed by the learners should be manifested through their class outputs and performances. The special features of the teacher guide are learning outcomes, planning for teaching and learning, possible techniques/strategies in teaching the lesson, learning competencies anchored on the curriculum guide of December 2013, and answer key. It provides the teachers with the necessary guide to be able to teach the lessons in a more creative, engaging, interactive and effective manner.

\section{Summary, conclusion, and recommendation}

This part presents the summary, findings, and conclusions that were drawn from the gathered data. The recommendations are also provided for further enhancement of the study. 


\subsection{Summary}

This study assessed the localized mathematics modules in achieving the learning competencies in Grades 7 and 9 and the difficulties met by teachers in the utilization of the modules with the end view of developing a teacher guide to enhance mathematics teaching and learning.

Specifically, the study will answer the following questions:

$>\quad$ What is the demographic profile of Grades 7 and 9 teachers of mathematics in terms of gender; highest educational attainment; years of teaching mathematics; and mathematics training/seminars attended?

$>\quad$ How do the teachers assess the localized mathematics modules in achieving the learning competencies in Grade 7 and 9?

$>\quad$ Are there significant differences in the assessments on the localized mathematics modules when teachers are grouped according to profile variables?

$>\quad$ What are the difficulties met in the utilization of the following localized learners' modules: Mathematics 7; and Mathematics 9?

$>\quad$ What teacher guide may be developed to enhance mathematics learning?

The respondents of this study were 123 Grade 7 mathematics teachers, and 115 Grade 9 mathematics teachers from public secondary schools in the Division of Batangas. The descriptive method of research was used using a questionnaires the main data gathering instrument. Frequency, percentage, composite mean, ANOVA and T-Test were used in the statistical treatment of data.

\subsection{Findings}

After the gathered data were analyzed, tabulated and statistically treated, the researchers arrived at the following findings: Profile of Grade 7 and 9 Mathematics Teachers - Majority of the Grades 7 and 9 mathematics teachers are female with 190 teachers or 79.83 percent. The remaining 20.17 percent or 48 teachers are male. Majority of Grades 7 and 9 mathematics teachers have units in master's degree, with 135 teachers or 56.72 percent. This was followed by the number of respondents with baccalaureate degree with 68 or 28.57 percent, those with master's degree with 31 or 13.03 percent and those with doctorate units with 4 or 1.68 percent. There was no respondent with a doctorate degree. Out of 238 respondents, teachers with 5 years or less teaching mathematics have the highest frequency of 114 or 47.90 percent. It was followed by 33 or 13.87 percent with 6 to 10 years of teaching experience in mathematics. Lastly, the respondents have been teaching for 31 years or more got the lowest frequency of 10 or 4.20 percent. Most of the Grades 7 and 9 mathematics teachers in the Division of Batangas are not actively participating in trainings and seminars in mathematics for the last four (4) years with the frequency of 173 or 72.69 percent. There were only 13 teachers or 5.46 percent who have been actively participating in trainings and seminars in mathematics.

Assessment of the Localized Mathematics Modules in Achieving the Learning Competencies by Grade Level - The composite means of 2.94, and 2.97 for the assessments of Grade 7 and 9 modules, respectively show that the localized mathematics modules generally conformed to the module/instructional materials evaluation criteria in terms of format, presentation and organization, and accuracy and up-to-date information.

Differences in the Assessments of the Localized Mathematics Modules when grouped according to Profile Variables - In the Grade 7 localized mathematics module, there are significance differences on the assessment of the content, illustrations, presentation and organization, and accuracy and up-to-date information when teachers are grouped as to gender. On the other hand, the teachers' assessments of prints in the Grade 9 localized 
mathematics module significant differed when grouped in terms of gender When grouped according to highest educational attainment, the assessments of format in terms of prints of the Grade 7 localized mathematics modules have significant differences. In the assessments of formats in terms of illustrations and design and layout, as well as accuracy and up-to-date information of Grade 9 localized mathematics modules, it was found out that there are significant differences in the assessments of teachers.

It was also found out that the assessments on all the factors aside from format in terms of prints of Grade 7 localized mathematics modules have significant differences. However, only in the assessments of the content of the Grade 9 localized mathematics modules have significant differences when the respondents are grouped in terms of years of teaching mathematics. Based on the findings, the assessments on the accuracy and up-to-date information of Grade 7 localized mathematics modules have significant differences while in the assessments on all the factors of Grade 9 localized mathematics modules, have no significant differences when the respondents are grouped according to training/seminars attended.

Difficulties Met in the Utilization of the Localized Learners Mathematics Modules - It was revealed that Grade 7 mathematics teachers agreed that the students do not have printed localized module, ranking first with a mean of 3.22. This statement ranked second for Grade 9 teachers with a mean of 2.83. There are no answer keys for each activity and evaluation which ranked second for grade 7 and ranked first for Grade 9 teachers. These have a computed means of 2.99 and 2.92, respectively. The statements such as there are some learning competencies which fail to be covered due to limited time, and that there are activities which are time consuming, ranked third in Grades 7 and 9, respectively.

On the other hand, Grade 7 mathematics teachers disagreed that the contents in the module are difficult to match with the format of the new daily learning log (DLL). They also disagreed that the objectives in the localized module are broad, that there are activities which are not suitable to mentally challenged learners, and there are terminologies which are not easy to understand as challenges or difficulties in the utilization of Grade 7 localized mathematics module. Moreover, Grade 9 teachers disagreed on the statements stating that the contents in the module are difficult to match with the format of the new daily learning $\log$ (DLL), the localized module requires extra planning time for teachers, the objectives in the localized module are broad, the real-life application of the lessons is not clearly stated, there are grammatical errors, there are terminologies which are not easy to understand, and there is no consistency of format of the text as challenges or difficulties in the utilization of Grade 9 localized mathematics module.

Teacher Guide for the enhancement of Mathematics Teaching and Learning - Grades 7 and 9 mathematics teachers need a teacher guide that contains the answer key for each activity and suggested strategies in the utilization of the localized mathematics modules that would help them cover the required topics and competencies in the prescribed time frame.

\subsection{Conclusions}

In light of the significant findings revealed in the study, the following conclusions were formed:

$>\quad$ Most Grades 7 and 9 teachers are female, have master's units of five years or less teaching experience, and are not active in attending trainings/seminars.

$>$ The localized mathematics modules for Grades 7 and 9 conform to the module/instructional materials evaluation criteria in terms of content, format, presentation and organization, and accuracy and up-to-date information.

$>$ There are differences on the respondents' assessments of the localized mathematics modules when grouped according to gender, highest educational attainment, years of teaching mathematics and mathematics trainings/seminars attended. 
$>\quad$ Grades 7 and 9 mathematics teachers experienced difficulty in utilizing the localized mathematics modules primarily because the students do not have printed localized module and there are no answer keys for each activity and evaluation.

$>\quad$ The developed teacher will be of help to the Grades 7 and 9 mathematics teachers in utilizing the localized mathematics modules.

\subsection{Recommendations}

Considering the significant findings revealed and conclusions drawn in this study, the following recommendations are offered.

$>\quad$ The developed teacher guide may be validated prior to adoption and utilization to maximize the use of localized mathematics modules.

$>\quad$ The school administrators must consider providing relevant trainings/seminars for mathematics teachers for continuous professional development.

$>\quad$ A parallel study may be conducted in other localized modules of other subjects.

\section{References}

Alegre, L. A. (2005). Development of enhancement program to address teaching difficulties in social studies [Unpublished Master's Thesis]. Philippine Normal University, Manila.

Almario, R. A. (2002). A validation of manual on selected topic in mathematics $V$ [Unpublished Doctoral Dissertation]. Eulogio “Amang” Rodriguez Institute of Science and Technology.

Anderson, M. C. (2003). Rethinking interference theory: Executive control and the mechanisms of forgetting. Journal of Memory and Language, 49(4), 415-445. https://doi.org/10.1016/j.jml.2003.08.006

Añonuevo, D. P., \& Manalo B. P. (2010). Sample modular-based computer-operated activity sheets: Offshoot for difficult learning tasks in mathematics 1 [Unpublished Thesis]. Batangas State University, Batangas City.

Bagcal, M. F. (2000). Self-perceived competencies of secondary schools teachers, Cotabato Division [Unpublished Master's Thesis]. NDU-NDMC, Cotabato.

Bautista, D. A. (2011). Personal qualities of mathematics teachers: Effects to achievement in mathematics of intermediate pupils in two schools of district of Cabuyao Laguna S. Y. 2009-2010 [Unpublished Master's Thesis]. Philippine Normal University, Manila.

Bico, A. A. (2016). Preparedness of mathematics teachers in the implementation of K to 12 Program in San Juan District, Division of Batangas [Unpublished Thesis]. Batangas State University, Batangas City.

Bueno, D. C. (2006). Common Problems in Mathematics as Perceived by Teachers and Students: Bases for Instructional Enhancement [Unpublished Master's Thesis]. Philippine Normal University, Manila.

Cafirma, R. A. (2008). Variables affecting the instructional competency of intermediate English teachers of Alaminos District [Unpublished Thesis]. Laguna State Polytechnic University, Laguna.

Canonizado, I. C. (2009). Why do some pupils find math hard? The Modern Teacher, 58(4).

Chapin, S. H. (2000). Math matters: Understanding the math you teach. Grades K-6. Math Solutions Publications.

Cochran-Smith, M. (2004). Walking the road race, diversity, and social justice in teacher education. New York, NY: Teachers College Press.

Dino, N. S. (2000). Scholastic performance and unified test in mathematics vis-a-vis instructional strategies [Unpublished Master's Thesis]. Harvadian Colleges, San Fernando, Pampanga.

Dossey, J., McCrone, S., Giordano, F., \& Weir, M. (2002). Mathematics methods and modeling for today's mathematics classroom. A contemporary approach to teaching grade 7-12. Pacific Grove, CA: Brooks/Cole.

Ferrer, R. M. (2011). Proposed supplementary materials for teaching general science in secondary schools in 
Batangas City [Unpublished Thesis]. Batangas State University, Batangas City.

Flores, I. M. (2005). Mathematics teaching competencies of faculty in colleges and universities in Batangas City: Basis for direction on continuing education [Unpublished Doctoral Dissertation]. Batangas State University, Batangas City.

Glisan, E. W., \& Shrum, J. L. (2005). Teacher's handbook: Contextualized language instruction (3rd ed.). Thomson Heinle.

Luistro, A. (2010). DepEd-Br. Armin reports on his first 100 days. Retrieved from https://www.officialgazette.gov.ph/2010/10/22/deped-br-armin-reports-on-his-first-100-days/

Manangan, R. Q. (2011). A proposed work-textbook in technical, mathematics for freshmen: It's acceptability [Unpublished Master's Thesis]. Eulogio “Amang” Rodriguez Institute of Science and Technology, Manila.

Medoff, L. (2013). Getting beyond "I hate math!" Resilience and Learning, 71(1), 44-48.

Novak, J. D., \& Gowin, D. B. (1984). Learning how to learn. Cambridge University Press. https://doi.org/10.1017/CBO9781139173469

Ocillos, R. M. (2006). Factors related to the mathematics performance of second year students of government secondary schools in Panganiban, Catanduanes, SY 2004-2005 [Thesis].

Petingco, M. (2000). Teaching competencies of teachers of Pigcawayan North District, Cotabato Division [Unpublished Master's Thesis]. USM-Kabacan, Cotabato.

Portacion, E. B. (2000). Teaching difficulties among beginning teachers in the division of Misamis Occidental

[Unpublished Master's Thesis]. Medina College, Ozamiz City.

Prensky, M. (2013). Our brains extended. Technology-Rich Learning, 70(6), 22-27.

Regional Memorandum No. 8 s. (2015). Retrieved from https://depedcalabarzon.ph/wp-content/uploads/2015/05/Regional-Memorandum-No.8-s.2015.pdf

Roblyer, M. D. (2000). The National Educational Technology Standards (NETS): A review of definitions, implications, and strategies for integrating NETS into K-12 curriculum. International Journal of Instructional Media, 27(2), 133.

Salazar, L. (2001). Teaching and learning mathematics. The Modern Teacher, 64(9), 365-370.

Tajonera, J. I. (2009). Development of proposed modelling activities in mathematics IV for secondary schools in the division of Occidental Mindoro [Unpublished Master's Thesis]. Batangas State University, Batangas City.

The New Book of Knowledge. (2003). Vol. 18, pp. 37-38. Danburry, CT: Grolier.

Tolentino, E. R. (2014). Readiness of secondary mathematics teachers in the implementation of K to 12 basic education program in Area 1, Division of Batangas [Unpublished Master's Thesis]. Batangas State University, Batangas City.

Tujan, A. A. (2004). Transformative education. IBON Partnership in Education for Development.

Tulio, C. D. (2008). Foundations of education 2: Historical, philosophical and legal. National Bookstore.

Villamor, O. B. (2003). Validation of worktext in college algebra with chemistry applications [Unpublished Master's Thesis]. Eulogio “Amang” Rodriguez Institute of Science and Technology, Manila.

Villasotto, H. S. (2000). Evaluation of the SEDP values education textbook: basis for a proposed supplementary instructional material [Unpublished Master's Thesis]. Philippine Normal University, Manila.

Wesley, E. H., \& Wronski, S. P. (2003). Teaching social studies in elementary school. Boston: DC Health.

Zuleta, H. (2008). An empirical note on factor shares. The Journal of International Trade \& Economic

Development: An International and Comparative Review, 17(3), 379-390.

https://doi.org/10.1080/09638190802137034 